\title{
Business cycle patterns in European regions *
}

\author{
Ana Gómez-Loscos ${ }^{\dagger}$ \\ M. Dolores Gadea $\ddagger$ \\ Eduardo Bandres $\S$ \\ Banco de España \\ University of Zaragoza \\ University of Zaragoza and Funcas
}

\begin{abstract}
The aim of this paper is threefold. First, we analyze the comovements of the business cycles of European regions. Second, we date these business cycles and identify clusters of regions with similar business cycle behavior, using Finite Mixture Markov models. Third, we develop a new index to measure within-country homogeneity. We find that comovement among regions is, on average, quite low, although it increased during the convergence process prior to the euro cash and after the onset of the Great Recession. We identify five different groups of European regions. We also find heterogeneity in the size of border effects.
\end{abstract}

JEL classification: C32, E32, R11

Keywords: business cycle dating, comovements, clusters, regions, Finite Mixture Markov models.

\footnotetext{
${ }^{*}$ We are grateful to S. Kaufmann for sharing her codes with us. We also thank L. J. Alvarez, A. Fuertes, G. Hewings, J. F. Jimeno and participants in the 56th ERSA, 42th SAEe and the 11th CFE conferences, the editor and an anonymous referee for their useful comments. M. D. Gadea acknowledges financial support from Funcas. The views expressed in this paper are the responsibility of the authors and do not represent those of the Banco de España or the Eurosystem.

†Corresponding author: Banco de España, Alcalá, 48, 28014 Madrid (Spain). Tel: +34 913385817 , fax: +34 915310059 and e-mail: agomezloscos@bde.es

${ }^{\ddagger}$ Department of Applied Economics, University of Zaragoza. Gran Vía, 4, 50005 Zaragoza (Spain). Tel: +34 9767 61842, fax: +34976761840 and e-mail: lgadea@unizar.es

${ }^{\S}$ Department of Applied Economics, University of Zaragoza. Gran Vía, 4, 50005 Zaragoza (Spain). Tel: +34 9767 61846, fax: +34976761840 and e-mail: ebandres@unizar.es
} 


\section{Introduction}

Regional considerations have been highly relevant for European institutions since the establishment of the European Economic Community and, indeed, there are regional policies aimed at diminishing interregional differences (the 'Cohesion Policy') 1 ! are employed. For instance, around a third of the total EU budget during the period 2014-2020 corresponds to the Cohesion Policy.

Valuable policy lessons can be learned from the study of regional features. Implementing national economic policies could bring about undesirable distortions in some regions and slow down their convergence processes. This issue is particularly important because GDP evolution is very different across European regions, as will be shown in this paper. Furthermore, several regions with different business cycle features, which may require policies adapted to their territorial specificities, are identified. From a EU perspective, the design of cohesion policies that increase regional competitiveness and foster economic growth and employment is very important (see European Commission, 2017). From an individual country perspective, in countries where public revenue and expenditure decisions have an important regional dimension, such as Germany and Spain, fiscal policy could be used to reduce within-country regional disparities.

In the existing literature, much effort has already been devoted to country analyses of the European business cycles. For instance, many papers have analyzed the business cycles of European Monetary Union (EMU) countries and the synchronization among them $2^{2}$ However, it has to be borne in mind that analyses at the country level may well hide very different regional cyclical developments. Studying the regional dimension of business cycles is therefore important to uncover the heterogeneity hidden in country analyses, as, e.g., Ramajo et al. (2008) show for the European regions, Park and Hewings (2012) for the US states, Hayashida and Hewings (2009) for Japan and Gadea et al. (2012) for Spain. Unfortunately, in spite of the importance of studying regional business cycles in Europe, the focus of the scant number of existing papers has been mainly on the synchronization of short-term fluctuations in economic activity $!^{3}$

Against this framework, the aim of this paper is threefold. First, we analyze the comovements of the business cycles of European regions. Second, using Finite Mixture Markov models, to compute regional business cycle datings that allow us to identify clusters of regions that show similar business cycle features. Third, to develop a new index to measure within-country homogeneity (border effects).

${ }_{1}^{1}$ http://ec.europa.eu/regional_policy/en/policy/what/investment-policy/

${ }^{2}$ See De Haan et al. (2008) for a survey.

${ }^{3}$ See Fatas (1997), Acedo-Montoya and de Haan (2008), Barrios et al. (2003) and Clark and van Wincoop (2001). Marino (2013) uses dynamic factor models. Ozyurt and Dees (2015) study the determinants of economic performance. Gadea et al. (2019) combine regime-switching models and dynamic model averaging to measure time-varying synchronization. See Bandres et al. (2017) for a review of this literature. 
Our analysis contributes to the existing literature in several ways. First, we employ a more comprehensive dataset than in most of the previous literature, both in terms of its temporal and geographical dimensions, and we use GDP as the measure of economic activity. On the temporal dimension, the existing literature only covers the period prior to the Great Recession and the sovereign debt crisis, two events that may have significantly changed business cycle synchronization in Europe. $4^{4}$ In this paper, we fill this gap by analyzing the evolution of regional business cycles in Europe and the comovements among them for a longer period, covering both events. On the geographical dimension, in this paper, we work with 213 NUTS 2 regions. Considering NUTS 2 regions is highly important because regions eligible for support from the Cohesion Policy are defined at the NUTS 2 level. This is in contrast with most of this literature, which considers a much less detailed geographical breakdown.

Second, while there are institutions that establish a chronology of recessions and expansions for the euro area as a whole and for individual countries, no business cycle dating has been carried out for European regions so far $5^{5}$ In this paper, we use a sophisticated methodology that dates the business cycles of regions and identifies clusters among them. Moreover, we use Finite Mixture Markov models (Frühwirth-Schnatter and Kaufmann, 2008). This methodology, which combines clustering techniques and Markov Switching models, allows us to overcome some data limitations and technical difficulties that arise in capturing business cycles with heterogeneous data. In contrast, the existing literature, typically employs very simple methodologies such as computing correlations of different measures of regional economic activity with respect to the country or to the European business cycle.

Third, some of the regional papers identify a border effect, regions belonging to the same country being more synchronized than regions belonging to different countries. Chung and Hewings (2015) suggest that identifying national elements is helpful to evaluate the relationship among regions. However, the literature has so far failed to provide a consensus on the relative importance of borders. We also propose a new index to measure within-country homogeneity or border effects, that takes into account both the regional business cycle datings and the number of regions of each country.

The main findings of our paper are the following. First, we find that regional growth rates are quite heterogeneous and the spatial correlation among them is quite low during the whole sample. Second, interestingly, we find a progressive increase of summary measures of correlation during the convergence process towards the creation of the euro area and a sharp

\footnotetext{
${ }^{4}$ The Great Recession was very costly in terms of wealth due to its severity, its duration and the fact that it was global. The severity of this episode, together with the subsequent slow pace of the recovery, has rekindled interest in business cycle analysis. See Gadea et al. (2017b).

${ }^{5}$ Applied to the US states, Hamilton and Owyang (2012) develop a framework for inferring common Markovswitching components in a panel data set with large cross-sectional and time-series dimensions and Owyang et al. (2005) apply a regime-switching model to state-level coincident indices to characterize state business cycles.
} 
rise of comovements among regions during the Great Recession. Third, we identify five different groups of European regions that share different business cycle characteristics. Fourth, we identify sizable border effects, namely, the degree of homogeneity of regional business cycles within countries is quite different.

The rest of the paper is organized as follows. In Section 2, we present the Finite Mixture Markov models methodology and the dataset used in this paper. In Section 3, we report the main results of our paper. The final section concludes.

\section{Data and methodology}

Business cycle analysis is usually carried out at the national level using long quarterly or monthly samples and datings are obtained with the Bry and Boschan (1971) algorithm and the Markov Switching models (Hamilton, 1989). In contrast, regional data are available for relatively short samples with an annual frequency. Our paper uses Finite Mixture Markov models that allow us to deal with technical difficulties that arise in capturing business cycles with short samples and heterogeneous data. In this section, we describe our dataset and the methodology we employ to establish a regional business cycle dating chronology for the European regions and to identify clusters of regions that share common features.

\section{$2.1 \quad$ Data}

The availability of regional data on a high frequency basis and for a long span is scarce. Therefore, to analyze regional business cycles, we employ annual real GDP data, as quarterly data are not available..$^{6}$ It has to be acknowledged that annual data are more reliable to establish robust facts about real economic activity in spite of the loss of information on short-term dynamics.

The nomenclature of territorial units for statistics (NUTS) is the territorial breakdown for compiling regional accounts in the EU 7 In this study, we consider 213 NUTS2 regions corresponding to 16 European countries, namely, the 12 euro area (EA12) member states [Austria (AT), Belgium (BE), Finland (FI), France (FR), Germany (DE), Ireland (IE), Italy (IT), Luxembourg (LU), the Netherlands (NL), Portugal (PT), Spain (ES) and Greece (EL)], 3 EU member states [Denmark (DK), Sweden (SE) and the UK (UK)] and Norway (NO), which is not a member state of the EU. The series are available from 1980 to 2011 8 This dataset is the most comprehensive in terms of regional coverage that has been used in this literature.

\footnotetext{
${ }^{6}$ Even if available, quarterly data are short series, not homogeneous across countries and, generally, constructed by interpolating annual data. See Parks and Hewings (2012) for a review of the role of data frequency.

${ }^{7}$ We use the NUTS 2013 classification which lists 98 regions at NUTS1 level, 276 regions at NUTS2 level and 1,342 regions at NUTS 3 level. More details in http://ec.europa.eu/eurostat/web/nuts/overview.

${ }^{8}$ Regarding Germany, the eastern Landers and Berlin are not included in our analysis given that we do not have data prior to 1991 .
} 
On the one hand, we analyze, for the first time, the possible effect of the Great Recession and the sovereign debt crisis on the regional business cycle of the European countries. On the other hand, we employ regions at the NUTS2 level, which are the geographical units eligible for support from the Cohesion Policy. The source is Cambridge Econometrics.

\subsection{Methodology}

The use of Finite Mixture Markov models, developed by Frühwirth-Schnatter (2006) and Frühwirth-Schnatter and Kaufmann (2008) ${ }^{9}$ is suitable for analyzing regional business cycles, as shown by Gadea et al. (2018). This methodology has several advantages over other techniques: it not only overcomes some difficulties that arise in capturing business cycles with short samples and heterogeneous data, but also allows us to date the turning points of the business cycle of the regions and cluster them according to their cyclical features. With this model-based clustering approach for multiple time series, we can jointly estimate all the parameters of the model, including the number and composition of groups of regions. One alternative would be to use a two-stage procedure, that is, to date regional business cycles and then, based on these results, to build clusters, with a subsequent loss of information.

Finite Mixture Markov models avoid the heterogeneity bias by grouping time series and pooling them within clusters. Only the series that show similar dynamic properties and similar cyclical features are pooled to estimate the parameters. We summary the main features of the methodology in what follows. For more details, see Gadea et al. (2018).

Let $y_{i t}$ be a set of time series from $t=1, \ldots, T$ for $i=1, \ldots, N, N$ being the number of regions which arise from $K$ groups, so that for each group, $k=1, \ldots, K$, we define an econometric model to capture its business cycle with the same parameters, $\theta$. This model is based on the Markovswitching (MS) approach, proposed by Hamilton (1989), which aims to characterize a series through a process of a mean conditioned on a state of nature. Changes in this mean allow us to identify expansions and recessions. We consider a MS autorregresive process for the GDP growth, computed as the first difference of its log.

We use a classical MS model with 2 states $(j=1,0)$ that define two possible means, $\mu_{i, 1}$ and $\mu_{i, 0}$, which are associated with expansion and recession phases, respectively. A $2 \times 2$ transition matrix governs regime shifts, where $\xi_{i, 11}$ and $\xi_{i, 00}$ represent the probability of being in expansion or recession, respectively, and remaining in the same state in the following period; $\xi_{i, 01}$ denotes the probability of switching from recession to expansion and $\xi_{i, 10}$ is the probability of switching from expansion to recession.

The methodology for clustering is as follows. A latent group indicator $S_{i}$ that denotes to

\footnotetext{
${ }^{9}$ Kaufmann (2010) applies this method to analyze the Austrian business cycle using a large set of series.
} 
which group $y_{i}$ belongs for all $t$ is introduced. That is,

$$
p\left(y_{i} \mid \theta_{S_{i}}\right)=\left\{\begin{array}{c}
p\left(y_{i} \mid \theta_{S_{1}}\right), S_{i}=1 \\
\ldots \\
p\left(y_{i} \mid \theta_{S_{K}}\right), S_{k}=K
\end{array}\right.
$$

In this framework, the number of groups, the allocation of each region to a given group and the group-specific parameters $\theta=\left(\theta_{1}, \ldots, \theta_{K}\right)$ are estimated from the data. We also define a probabilistic model for $P\left(S_{i}=k\right)$.

Having combined the MS model for business cycle dating and the finite mixture for clustering, the basic model is the following:

$$
y_{i t}=\mu_{S_{i}}^{G}+\delta_{1, S_{i}}^{G} y_{i, t-1}+\ldots+\delta_{p, S_{i}}^{G} y_{i, t-p}+\left(I_{S_{i}, t}-1\right)\left(\mu_{S_{i}}^{R}+\delta_{1, S_{i}}^{R} y_{i, t-1}+\ldots+\delta_{p, S_{i}}^{R} y_{i, t-p}\right)+\epsilon_{i t}
$$

where $y_{i t}$ represents the GDP growth rate of region $i$ in time $t$ and $p$ the order of the autoregressive dynamics. Therefore, $\mu_{S_{i}}^{G}$ and $\delta_{j, S_{i}}^{G}$ for $j=1, \ldots p$ are the group-specific effects and $\mu_{S_{i}}^{R}$ and $\delta_{j, S_{i}}^{R}$ the state-specific effects, which are also group-specific. The group indicator is defined as $S_{i}=k$ with $k=1 \ldots K$. Periods of expansion (above-average growth periods) are denoted by $I_{S_{i}, t}=1$ with intercept $\mu_{S_{i}}^{G}$ and periods of recession (below-average growth periods) are denoted by $I_{S_{i}, t}=0$ with intercept $\mu_{S_{i}}^{G}-\mu_{S_{i}}^{R}$. We consider that the autoregressive dynamic is different for each group, thus $\delta_{j, S_{i}}^{G}$ and $\delta_{j, S_{i}}^{G}-\delta_{j, S_{i}}^{R}, j=1, \ldots p$. Defining $\varphi=(\theta, \eta, \xi)$, we estimate the set of state-specific and group-specific parameters $\theta$, the transition matrix $\xi_{S_{i}, j j}$, the group probabilities, $\eta=\left(\eta_{1}, \ldots, \eta_{K}\right)$. Disturbance terms have unit-specific variances $\epsilon_{i t} \sim N\left(0, \sigma_{i}^{2}\right)$ with $\sigma_{i}^{2}=\sigma^{2} / \lambda_{i}$.

The estimation technique, within a Bayesian framework, is Markov chain Monte Carlo. Specifically, each time series is, firstly, classified in one of the $K$ groups by sampling the group indicator $S_{i}$ from the posterior distribution $P\left(S_{i}=k \mid y, \varphi\right)$ and, secondly, conditional on known indicators $S=\left(S_{1}, \ldots, S_{K}\right)$, the estimation of the parameters is carried out by sampling them from the posterior probabilities $p(\varphi \mid S, y) .10$ The number of components, $K$, is selected considering four methods: a visual inspection of the point-process representation (scatterplots of the MCMC) and three maximum likelihood criteria (importance sampling, bridge sampling and reciprocal sampling). This selection process also includes the number of lags, $p$, that ranges from 0 to 2. To avoid label-switching problems, we use a combination of two restrictions. The first one assumes that the mean in expansions is higher than the mean in recessions $\left(\mu_{K}^{R}>0\right.$,

10 For estimation purposes, 5,000 draws and non-informative priors are considered. We follow the approach of Frühwirth-Schnatter and Kaufmann (2008). All the calculations have been done using the Matlab Toolbox of Frühwirth-Schnatter (2008). We use independent priors with the hyperparameters recommended by FrühwirthSchnatter and Kaufmann (2008). $\eta_{1}, \ldots, \eta_{k} \sim D(1, \ldots 1) ; \sigma^{2} \sim G^{-1}(1,1) ; \lambda_{i} \sim G(4,4) ; \xi_{S_{i}, j j} \sim B(3,1), j=1,2$; $\mu_{S_{i}}^{G} \sim N(0,4)$ and $\mu_{S_{i}}^{G}-\mu_{S_{i}}^{R} \sim N(0,4) ; \delta_{l, S_{i}}^{G} \sim N(0,1) ; \delta_{l, S_{i}}^{G}-\delta_{l, S_{i}}^{R} \sim N(0,1) ; l=1, \ldots, p$, for $k=1, \ldots, K$, where $D$ denotes a Dirichlet distribution; G, a Gamma distribution; and $B$, a Beta distribution. 
$\forall K)$. The second one identifies states within each cluster using different groups of parameters by imposing three alternative restrictions. See the details in the first column of Table 1 . The groupings obtained with each of the three combined restrictions are evaluated according to different criteria: (i) Mean probability of regions assigned to a group according to the highest probability; (ii) Mean probability of regions assigned to a group according to a probability above 0.5; (iii) Mean probability of non-assigned regions with a probability lower of 0.5 and (iv) Percentage of regions that are not unambiguously assigned because their maximum probability is below 0.5. The definition of these criteria is based on the concept of entropy and aims at guaranteeing the quality of the classification.

\section{Empirical results}

In this section, we examine our regional dataset and analyze the comovements of the regions during the sample. Then, we obtain, for the first time in the literature, a business cycle dating of the European regions and classify them into different clusters. Finally, on the basis of the previous results, we propose a new index to measure within-country homogeneity.

We have the following hypotheses: $\left(H_{1}\right)$ we expect that the Great Recession combined with the European debt crisis have had an impact on the dynamics of comovements; $\left(H_{2}\right)$ given the wide set of data, we expect to find several clusters among the European regions; $\left(H_{3}\right)$ given that the neighboring regions tend to be more similar, we expect some of the clusters to be geographically located and; $\left(H_{4}\right)$ given the idiosyncrasy within each country, we expect border effects to be sizable.

\subsection{Dynamics of European regional business cycles}

To get an overview of our regional data, which consists of 213 regions and 32 years, we calculate the kernel density of the regional growth rates for each year of our sample. Figure 1 shows the density once the outliers have been removed ${ }^{11}$ We observe great heterogeneity in GDP growth rates among regions.

After eliminating outliers, we analyze the patterns of comovements in the regional series. The upper part of Figure 2 represents regional GDP growth rates (blue lines) together with the median and the first and the third quartiles (red lines) of the series. In spite of the great number of series and their high variability, we can observe quite a smooth cyclical path in which the most outstanding event is the Great Recession.

\footnotetext{
${ }^{11}$ In order to remove them and maintain the signal of cyclical phases, we have linearly interpolated the observations that are four times or more above the standard deviation over the median of each regional time series. Using this methodology, we identify just six outliers.
} 
In order to analyze how the series move together over the sample, we compute Moran's modified statistic, following Stock and Watson (2008), which summarizes the possible timevarying comovements among GDP growth rates.

The measure is based on Moran's spatial correlation index and captures the comovements over time across all the regions through the rolling cross-correlation of logarithmic growth rates. It has the following expression:

$$
\begin{aligned}
& \widehat{I}_{i}=\frac{\sum_{i=1}^{N} \sum_{j=1}^{i-1} \operatorname{cov} \widehat{\left(y_{i t}, y_{j t}\right)} / N(N-1) / 2}{\sum_{i=1}^{N} \widehat{\operatorname{var}\left(y_{i t}\right) / N}} \\
& \left.\widehat{\operatorname{cov}\left(y_{i t}, y_{j t}\right.}\right)=\frac{1}{k} \sum_{s=t-i n t(k / 2)}^{t+i n t(k / 2)}\left(y_{i s}-\overline{y_{i t}}\right)\left(y_{j s}-\overline{y_{j t}}\right) \\
& \widehat{\operatorname{var}\left(y_{i t}\right)}=\frac{1}{k} \sum_{s=t-i n t(k / 2)}^{t+i n t(k / 2)}\left(y_{i s}-\overline{y_{i t}}\right)^{2} \\
& \overline{y_{i t}}=\frac{1}{k} \sum_{s=t-i n t(k / 2)}^{t+i n t(k / 2)} y_{i s}
\end{aligned}
$$

where $y_{i t}$ is the real GDP growth of region $i$ in time $t, k=5$ is the rolling window and $N=213$.

The results are displayed in the bottom part of Figure 2. We observe that the synchronization of comovements among regions is slightly above 0.20 , on average. The time series of this index shows that spatial correlation progressively increased during the convergence process towards the European Monetary Union and increased substantially as a consequence of the Great Recession, reaching a value of $0.70{ }^{12}$ confirming $H_{1}$. If we compute this index for the European countries, we find that the synchronization of comovements is around 0.50 , on average, much higher than for European regions, reflecting the relevance of region-specific shocks. Using country data, we also find a mild upward trend, briefly interrupted after the introduction of the euro, and a sharp increase at the time of the Great Recession.

\subsection{Dating and clustering European regional business cycles}

To obtain regional business cycle datings and to determine groups of regions, we estimate Finite Mixture Markov models, as previously described in Section 2. To select the best model, we estimate the log-marginal likelihood of different Markov Switching specifications considering different parameters for each group $(\mathrm{K}=1, \ldots, 6$ and $\mathrm{p}=0, \ldots, 2)$. Three sampling likelihood criteria are considered: importance sampling, bridge sampling and reciprocal sampling. All

\footnotetext{
${ }^{12}$ Gadea et al. (2017a) obtain similar conclusions using a methodology that combines Markov Switching models and dynamic model averaging.
} 
three methods agree that the preferred model for European regions includes two lags of GDP and identify five groups, i.e. $\mathrm{p}=2$ and $\mathrm{K}=5$, respectively 13 Furthermore, by analyzing the distribution of the posterior draws of the Markov Chain Monte Carlo processes for the different parameters following a Bayesian estimation, we are able to distinguish five clear clusters of European regions, confirming the previous model specification.

Regarding the identification of groups, we asses the accuracy of the different methods for each number of clusters to properly assign the regions to a specific group and avoid labelswitching problems. The first restriction is that the mean of expansions must be higher than the mean of recessions $\left(\mu_{K}^{R}>0, \forall K\right)$ and it is combined with three other restrictions that identify states within each cluster using different parameters. The first identifies clusters by setting a restriction on the autoregressive parameters, that is, to order the groups from the lowest to the highest persistence of expansionary phases $\left(\delta_{G}(1)<\delta_{G}(2)<\ldots<\delta_{G}(K)\right)$, the second classifies groups from the lowest to the highest growth rates in recessions $\left(\mu_{R}(1)<\mu_{R}(2)<\ldots<\mu_{R}(K)\right)$ and the third orders the clusters from the highest to the lowest growth during expansions $\left(\mu_{G}(1)>\mu_{G}(2)>\ldots>\mu_{G}(K)\right)$. All the details on the identification of groups according to different criteria can be found in Table 1

We find that, considering $\mu_{G}(1)>\mu_{G}(2)>\ldots>\mu_{G}(K)$, we get a classification of $100 \%$ of the regions with $K=5$. The identification of five groups of regions is very robust in spite of the fact that all criteria have a bias towards identifying the smallest number of groups as, by construction, the percentage of assigned regions increases as $K$ decreases, by reaching the $100 \%$ when $K=14$ The posterior classification probabilities are displayed in Figure 3 . For most regions, the classification probability into one group is close to one ${ }^{15}$ However, some regions (mainly, French and British) belonging to the fourth group are classified with nearly equal probability into the fourth and the fifth group.

The geographical distribution of regional business cycles into different groups is displayed in Figure 4. The first group is made up of all the Greek regions but one (12 regions in total), so we refer to it as the Greek group; in the second group, we find mostly German regions (11) -half of them, in the south of the country-, plus one Italian and one Portuguese region (13 regions in total), and we label it the southern Germany group; the third group includes some German (8) -located, mainly, in the northwest of the country-, Belgian (2) and Dutch (3) regions as well as one Austrian and one Portuguese region (15 regions in total), which we call the core group; the fourth group contains most of the UK regions (21), all the Swedish and Finnish regions (8 and 5, respectively), one Dutch region, one Spanish region and the four French overseas regions (40 regions in total), and we call it the northern group and, finally, the fifth group is the largest

\footnotetext{
${ }^{13}$ Marginal likelihoods are available upon request.

${ }^{14}$ In fact, the only region with a probability of being assigned below 0.5 is the Portuguese region of Alentejo (PT18). Its most likely location (probability of 0.44 ) is in the fifth group.

${ }^{15}$ We list the probabilities of belonging to each group of all the regions by country in Appendix 1.
} 
and is composed of the remaining regions (132 regions in total), which we refer to as the largest group. This classification seems to be related, at least partially, with the geographical location, as expected in $\mathrm{H}_{3}$. In the last column of Table 2, we note that the number of regions clearly differs among groups, the largest one comprising more than $60 \%$ of the total number of regions.

Table 2 summarizes the posterior estimates for the parameters of interest of the chosen model specification for the European regions. It can be observed that intercepts during expansions and recessions $\left(\mu_{S_{i}}^{G}\right.$ and $\mu_{S_{i}}^{G}-\mu_{S_{i}}^{R}$, respectively) clearly differ among groups. There are different mean growth rates in expansion, as can be seen from the $\mu_{S_{i}}^{G}$ values of the five groups, whereas the mean growth rates in recession, $\mu_{S_{i}}^{G}-\mu_{S_{i}}^{R}$, are broadly similar across groups. The growth rates for each group during expansionary phases are the following: $2.15 \%$ in the Greek group, $1.73 \%$ in the southern Germany group, $1.26 \%$ in the core group, $1.07 \%$ in the northern group and $0.49 \%$ in the largest group. Meanwhile, the mean growth rates during recessionary phases are $-0.45 \%$ in the Greek group, $-1.07 \%$ in the southern Germany group, $-1.57 \%$ in the core group, $-1.77 \%$ in the northern group and $-2.21 \%$ in the largest group.

For a better understanding of the features characterizing each group, in Figure 5, we present the quartiles of the average GDP growth distribution for each group, along with the minimum and maximum values of each series and their outliers. We observe that the Greek group has the lowest average GDP growth and the highest variance. The other groups are quite homogeneous with regard to their average growth rates and variability ${ }^{16}$ However, if we compute the boxplots for above-average (expansions) and below-average (recessions) periods of average real GDP growth, we find a greater heterogeneity among groups (see Figure 6). For instance, the Greek group shows the highest growth rates during expansions and the lowest ones during recessions.

We have computed the Moran-Stock-Watson index of comovements, proposed in the previous subsection, for just the first four groups of regions. We find that the main results still hold. Specifically, comovement among regions is still, on average, quite low. It increased during the convergence process prior to the euro cash changeover and after the onset of the Great Recession 17

Additionally, the persistence of the states $I_{t}=1$ and $I_{t}=0$ ( $\xi_{11}^{S_{i}}$ and $\xi_{00}^{S_{i}}$, respectively), that is, the probability of being in expansion (recession) conditional upon being in expansion (recession) in the previous period is quite similar among the groups ${ }^{18}$ However, we observe that the series are more persistent during periods of economic recovery than during periods of economic slowdown. It should be noted that expansionary periods are more persistent in the northern and the largest groups than in the others, the least persistent recoveries being in the Greek group. The persistences for each group of expansionary phases are 0.7 in the

\footnotetext{
${ }^{16}$ However, the core group, has one atypical region and the largest group has the highest number of outliers, five, that all belong to different countries.

${ }^{17}$ Results are available upon request.

${ }^{18}$ State persistence is not significantly different across groups.
} 
Greek group, 0.73 in the southern Germany group, 0.79 in the core group, 0.83 in the northern group and 0.86 in the largest group. The persistences of recessionary phases are 0.56 in the Greek group, 0.55 in the southern Germany group, 0.57 in the core group, 0.67 in the northern group and 0.57 in the largest group. Regarding autorregresive persistence, the values of the parameters show that the series do not have a unit root.

The probability of being in recession is estimated separately for each of the five groups in Figure 7. It should be pointed out that there are two recessionary periods that are common to the five groups, namely, that at the beginning of the nineties and that during the Great Recession. The deceleration at the beginning of the 2000s decade mainly affected the regions in the southern Germany and the core groups (and, to a lesser extent, the Greek group). The probability of being in recession of the Greek group, the southern Germany group and the core group also reflects an additional period of growth slowdown in the mid 1980s, after the economic instability of the 1970s that was due to the different oil price shocks.

We compute a recession diffusion index, defined as the percentage of clusters in recession, to see the evolution of the number of groups that are in recession in each year of our sample (Figure 8). The index confirms the two above-mentioned common recessionary shocks, one at the beginning of the nineties and the other associated with the Great Recession. Other recessionary periods only affected specific groups. We do not observe any pattern in cluster similarity of business cycle datings after the introduction of the euro.

The detailed business cycle of each group is depicted in Figure 9, representing recessions and expansions ( $I_{t}=0$ and $I_{t}=1$, respectively). There are some remarkable differences in the cyclical performance of the different groups.

1. Regions belonging to the Greek group are in recession for a large part of the sample (eleven years out of thirty one), the southern Germany and the core groups underwent downturns in nine years of the sample, the northern group was in recession during eight years and regions in the largest group suffered only four recessionary years.

2. All the groups underwent the Great Recession, but with a different severity. The greatest intensity is registered in the Greek group, in which the recession began in 2008 and continued without interruption until 2011, the last year of our sample. However, in the remaining groups, either the Great Recession ended earlier or it hit again after a short expansion, causing a double dip. Furthermore, in the core group, it arrived a year later (2009) than in the other groups.

3. The crisis at the beginning of the nineties is also present in all the groups, but with a different timing and duration in each of them. The longest duration of the recession was in the southern Germany and the northern groups (four years) and the shortest in the largest group, where it lasted for one year. 
4. The deceleration of the beginning of the 2000s decade appeared in the second and third groups, which include most of the German regions, during 2002 and 2003, although the Greek group also experienced a brief recession in 2005. The deceleration of 2001 did not affect regions belonging to the northern and the largest groups.

5. We find important differences in the aftermath of the oil crises, that is, during the slowdown of the mid-eighties. The Greek and the core groups suffered a recession in the first year of the sample. After 1985, one or two years of slowdown are also observed in the Greek, the southern Germany and the core groups.

6. There are fewer recessions in the northern and the largest groups than in the rest of the groups. This might be due to their economic size, given that region-specific shocks could play a less relevant role in driving the business cycle.

Finally, the stylized features characterizing the intensity of the cyclical phases of the five groups of European regions can be summarized as follows.

1. The two phases of the business cycle are clearly distinguished in all the groups, although the dispersion across groups is higher during periods of recovery than during periods of recession, in line with regional literature 19 The growth rate during expansion ranges from $0.49 \%$ in the largest group to $2.15 \%$ in the Greek group, while the growth rate during recessions ranges from $-2.84 \%$ in the northern group to $-2.6 \%$ in the Greek group. In order to interpret these figures, it has to be borne in mind that regions in the Greek group are in recession most of the time so, in spite of the high growth rate during expansion, they do not have a better performance in terms of accumulated growth. On the contrary, regions in the largest group only experience a recession during four years and are especially intense during the three years of the Great Recession.

2. The mean persistence of the states is higher during expansions than during recessions and both are quite homogeneous among the groups. The persistence, i.e., the probabilities of remaining in each state, range from $0.7 \%$ in the Greek group to $0.86 \%$ in the largest group during recoveries and from $0.55 \%$ in the southern Germany group to $0.67 \%$ in the northern group during recessions.

\subsection{Within-country homogeneity}

The literature has paid attention to whether business cycles across regions of the same country tend to be more correlated than business cycles across regions of different countries or not,

\footnotetext{
${ }^{19}$ Chung (2016) finds more coordination during periods of recession for the US states. Also for the US states and cities, Owyang et al. (2005 and 2008) further investigate the determinants of the average growth rates of the two cyclical phases.
} 
a phenomenon called "border effect". Some potential explanations for the existence of this border effect are sectoral specialization (given that regions within a country tend to have more similar production structures than regions in different countries), trade (which it is related to distance, culture, language and institutions), monetary policy (to the extent that monetary policy shocks are a source of business cycles, one would expect that a single policy would lead to higher business cycle synchronization) 20 and fiscal policy (since decentralized fiscal systems could help to reduce economic disparities within a country and, thus, increase synchronization). However, there is lack of consensus in the literature about the effect of national borders. For instance, Clark and van Wincoop (2001) and Acedo-Montoya and de Haan (2008) support the existence of border effects, whereas Fatas (1997) finds low within-country correlations ${ }^{21}$

To get a better understanding of the spatial dimension of European regional synchronization, we propose a new measure to test the homogeneity of regional business cycles within country with the outcomes of Finite Mixture Markov models. This allows us to identify the countries containing regions with more homogeneous business cycles. We propose an index $I_{c}$ of Regional business cycle homogeneity that it is computed for each country c, as follows:

$$
\begin{aligned}
I_{c} & =\sum_{i=1}^{K} \operatorname{share~}_{i} * \operatorname{prob}_{i} * w_{i} \\
\text { share }_{i} & =\frac{1}{N R_{c}} \sum_{j=1}^{N R_{c}} I_{j i} \\
\text { prob }_{i} & =\frac{1}{N R_{c}} \sum_{j=1}^{N R_{c}} P_{j i}
\end{aligned}
$$

- where $I_{j i}$ is a dummy variable that takes value 1 if a region $j$ belongs to group $i$ and 0 otherwise, $N R_{c}$ being the number of regions in country $c$.

- $P_{j i}$ is the probability of region $j$ of belonging to group $i$.

- $w_{i}$ is the weight assigned to regions of belonging to each group $i$. These weights have been calculated in two alternative ways. Firstly, we have used the GDP share of those

\footnotetext{
${ }^{20}$ This explanation is less clear due to the fact that common policies do not allow flexibility to dampen country-specific shocks.

${ }^{21}$ Although not strictly comparable to our results, as they use less disaggregated datasets and different methodologies, Clark and van Wincoop (2001) confirm the existence of a border effect in some French and German regions. Acedo-Montoya and de Haan (2008), using clustering techniques and a sample 53 NUTS1 regions (12 countries), find that most of the regions belonging to the same country are closely synchronized. However, both of these findings contradict those of Fatas (1997) who suggests that correlation within countries is not very high and has reduced over time for 38 NUTS2 regions (4 countries). Note this sample does not include the common monetary period.
} 
regions in a country belonging to a given group ${ }^{22}$ Secondly, we consider a weighting matrix that penalizes within-country heterogeneity. We have named these alternatives, GDP and density weighted, respectively.

The closer the value of the index is to 0 , the higher is the degree of heterogeneity, while the closer the value is to 1 , the higher is the degree of homogeneity ${ }^{23}$. This index is based on the clustering procedure applied to regional economic cycles. It combines information on the number of regions of a country that are in the same cluster, and the probability of each region of belonging to that cluster. Therefore, it is different from other measures of regional synchronization, such as a standard deviation of regional growth rates, that do not take into account the dating of the business cycle. Results are displayed in Figure 10 for the original index along with the two alternative indexes, that take into account different weights.24

The within-country business cycle similarity is quite high in most countries. Indeed, the value of the original index is above 0.50 in twelve of them (blue bars in Figure 10). The highest values correspond to NO and DK and the lowest to DE, PT and the UK. There are two factors that help explain the low value of the homogeneity index for DE and the UK. On the one hand, these countries have a larger number of regions. On the other hand, regions in these countries do not tend to be clearly assigned to a unique cluster.

The results of the GDP weighted index are shown in the yellow bars in Figure 10. The main results remain qualitatively the same. However, using this GDP weighted index, we find that the degree of internal synchronization of the UK, DE and NL is much lower than the one calculated with the original index.

Finally, the ranking of the business cycle homogeneity by country obtained using the density weighted index (red bars in Figure 10) is the same as the rankings computed using the two previous alternatives. Nevertheless, taking into account this index, there are large differences in the degree of business cycle homogeneity in IT, ES and EL compared to the figures obtained with the original index, showing a lower degree of internal synchronization. The dispersion of the values is higher in the case of the two corrected indexes.

\section{Concluding remarks}

In this paper, we analyze the comovements of the business cycles of European regions. We also date the business cycles of European regions and identify clusters among the regions showing

\footnotetext{
${ }^{22}$ We appreciate the comments of an anonymous referee in the construction of the index.

${ }^{23} \mathrm{~A}$ country whose regions are all located in a group with probability 1 will have an index equal to 1 . On the other hand, a country whose regions are not clearly located (probability $>0.5$ ) in any group will have an index equal to 0 .

${ }^{24}$ The results of Luxembourg have been removed from this figure because, being a one-region country, the construction of this index would not make any sense.
} 
similar business cycle behavior, using Finite Mixture Markov models for the regional analysis. This methodology allows us to overcome some data limitations and technical difficulties that arise in capturing business cycles with heterogeneous data. Additionally, we propose an index to measure within-country homogeneity or border effects. All the analyses are done employing a more comprehensive dataset than in most of the previous literature, both in terms of temporal and geographical dimensions.

The main findings of the paper are the following. Comovement among regions is, on average, quite low. However, we find a progressive increase of the spatial correlation during the convergence process towards the creation of the euro area and a sharp rise of comovements among regions during the Great Recession. We identify five groups of European regions with different timings and intensities of their cyclical phases. We also find sizable border effects, i.e, the degree of homogeneity of regional business cycles within countries is quite different.

The similarity of regional business cycles in Europe is an important criterion for implementing common European policies. For instance, common policies might not be equally good for all the regions if there is heterogeneity in business cycle developments across regions. In turn, idiosyncratic features should be addressed taking into account the regional dimension by using either the Cohesion Policy or region-specific national policies.

\section{Compliance with Ethical Standards}

Conflict of interest: M. D. Gadea has received financial support from Funcas. A. Gomez Loscos and E. Bandres declare that they have no conflict of interest.

Ethical approval: This article does not contain any studies with human participants or animals performed by any of the authors. 


\section{References}

[1] Acedo-Montoya, L.A. and de Haan, J. (2008). Regional business cycle synchronization in Europe?, International Economics and Economic Policy, 5(1-2), 123-137.

[2] Bandres, E., Gadea-Rivas, M. D. and Gomez-Loscos, A. (2017). Regional business cycles across Europe, Occasional Paper, Banco de España 1702.

[3] Barrios, S., Brulhart, M., Elliott, R.J.R. and Sensier, M. (2003). A tale of two cycles: co-fluctuations between UK regions and the euro zone, The Manchester School, 71(3), 265-292.

[4] Bry, G. and Boschan, C. (1971). Cyclical analysis of time series: selected procedures and computer programs, NBER, New York.

[5] Chung, S. (2016). Assessing the regional business cycle asymmetry in a multi-level structure framework. a study of the top 20 US MSAs, Annals of Regional Science, 56, 229-252.

[6] Chung, S. and Hewings, G. J. D. (2015). Competitive and complementary relationship between regional economies: a study of the Great Lake states, Spatial Economic Analysis, $10(2), 205-229$.

[7] Clark, T. E. and van Wincoop, E. (2001). Borders and business cycles, Journal of International Economics, 55, 59-85.

[8] de Haan, J., R. Inklaar, and Richard, J. (2008). Will business cycles in the Euro Area converge: a critical survey of empirical research, Journal of Economic Surveys, 22(2), $234-273$.

[9] European Commission (2017). My Region, My Europe, Our Future. Seventh report on economic, social and territorial cohesion, Publications Office of the European Union, Luxembourg.

[10] Fatas, A. (1997). Countries or regions? Lessons from the EMS experience. European Economic Review, 41, 743-751.

[11] Frühwirth-Schnatter, S. (2006). Finite Mixture and Markov Switching Models, New York: Springer-Verlag, 1st edn.

[12] Frühwirth-Schnatter, S. and Kaufmann, S. (2008). Model-based clustering of multiple time series, Journal of Business and Economic Statistics, 26, 78-89. 
[13] Gadea, M. D., Gómez-Loscos, A. and Bandres, E. (2018). Clustering regional business cycles, Economics Letters, 162, 171-176.

[14] Gadea, M. D., Gómez-Loscos, A. and Leiva-Leon, D. (2017a). The evolution of regional economic interlinkages in Europe, Working Paper, Banco de España 1705.

[15] Gadea, M. D., Gómez-Loscos, A. and Leiva-Leon, D. (2019). Increasing linkages among European regions. The role of sectoral composition, Economic Modelling, 80, 222-243.

[16] Gadea, M. D., Gomez-Loscos, A, and Montañes, A. (2012). Cycles inside cycles: Spanish regional aggregation, SERIEs, Journal of the Spanish Economic Association, 3(4), 423-456.

[17] Gadea, M. D., Gomez-Loscos, A., and Perez-Quiros, G. (2017b). Dissecting US recoveries, Economics Letters, 154, 59?63.

[18] Hamilton, J.D. (1989). A new approach to the economic analysis of nonstationary time series and the business cycle, Econometrica, 57(2), 357-84.

[19] Hamilton, J.D. and Owyang, M.T. (2012). The propagation of regional recessions, The Review of Economics and Statistics, 94(4), 935-947.

[20] Harding, D. and Pagan, A. (2002). Dissecting the cycle: a methodological investigation, Journal of Monetary Economics, 49(2), 365-381.

[21] Hayashida, M. and Hewings, G. J. D. (2009). Regional business cycles in Japan, International Regional Science Review, 32(2), 119-147.

[22] Kaufmann, S. (2010). Dating and forecasting turning points by Bayesian clustering with dynamic structure. A suggestion with an application to Austrian data, Journal of Applied Econometrics, 25, 309-344.

[23] Marino, F. (2013). Regional fluctuations and national cohesion in the EU12: a preMaastricht assessment, SERIES Working Papers 48, University of Bari.

[24] Owyang, M.T, Piger, J. and Wall, H. J. (2005). Business cycle phases in U.S. states, The Review of Economics and Statistics, 87(4), 604-616.

[25] Owyang, M.T, Piger, J., Wall, H. J. and Wheeter, C. (2008). The economic performance of cities: A Markov Switching approach, Journal of Urban Economics, 64(3), 538-550.

[26] Ozyurt, S. and Dees, S. (2015). Regional dynamics of economic performance in the EU: To what extent spatial spillovers matter?, European Central Bank Working Paper 1870. 
[27] Park, Y. and Hewings, G. J. D. (2012). Does industry mix matter in regional business cycles?, Studies in Regional Science, 42(1), 39-60.

[28] Ramajo, J., Marquez, M.A., Hewings, G. and Salinas, M.M. (2008). Spatial heterogeneity and interregional spillovers in the European Union: Do cohesion policies encourage convergence across regions?, European Economic Review, 52, 551-567.

[29] Stock, J. and Watson, M. (2008). The evolution of national and regional factors in U.S. housing construction. In: Bollerslev ,T., Russell, J. abd Watson, M., Volatility and Time Series Econometrics: Essays in Honor of Robert F. Engle. Oxford University Press. 


\section{Tables}

Table 1: Identification strategy

\begin{tabular}{l|c}
\hline \hline Method/Groups & $\mathrm{K}=5$ \\
\hline \multicolumn{1}{c}{ Highest probability criterion $^{(\mathrm{a})}$} \\
\hline$\mu_{K}^{R}>0, \forall K$ & - \\
$\delta_{j, 1}^{G}<\delta_{j, 2}^{G}<\ldots<\delta_{j, K}^{G} \forall j=1, \ldots, p$ & 0.88 \\
$\mu_{1}^{R}<\mu_{2}^{R}<\ldots<\mu_{K}^{R}$ & 0.58 \\
$\mu_{1}^{G}>\mu_{1}^{G}>\ldots>\mu_{K}^{G}$ & 0.86 \\
\hline \multicolumn{2}{c}{ Above 0.5 probability criterion ${ }^{(\mathrm{b})}$} \\
\hline$\mu_{K}^{R}>0, \forall K$ & - \\
$\delta_{j, 1}^{G}<\delta_{j, 2}^{G}<\ldots<\delta_{j, K}^{G} \forall j=1, \ldots, p$ & 0.88 \\
$\mu_{1}^{R}<\mu_{2}^{R}<\ldots<\mu_{K}^{R}$ & 0.75 \\
$\mu_{1}^{G}>\mu_{1}^{G}>\ldots>\mu_{K}^{G}$ & 0.86 \\
\hline \multicolumn{2}{c}{ Non-assigned regions $(\%)^{(\mathrm{c})}$} \\
\hline$\mu_{K}^{R}>0, \forall K$ & - \\
$\delta_{j, 1}^{G}<\delta_{j, 2}^{G}<\ldots<\delta_{j, K}^{G} \forall j=1, \ldots, p$ & 0.44 \\
$\mu_{1}^{R}<\mu_{2}^{R}<\ldots<\mu_{K}^{R}$ & 0.41 \\
$\mu_{1}^{G}>\mu_{1}^{G}>\ldots>\mu_{K}^{G}$ & 0.41 \\
\hline Non-unambiguously assigned regions $(\%)^{(\mathrm{d})}$ \\
\hline$\mu_{K}^{R}>0, \forall K$ & - \\
$\delta_{j, 1}^{G}<\delta_{j, 2}^{G}<\ldots<\delta_{j, K}^{G} \forall j=1, \ldots, p$ & 0.01 \\
$\mu_{1}^{R}<\mu_{2}^{R}<\ldots<\mu_{K}^{R}$ & 0.25 \\
$\mu_{1}^{G}>\mu_{1}^{G}>\ldots>\mu_{K}^{G}$ & 0.00 \\
\hline \hline
\end{tabular}

Notes: The first column shows the assignation of regions when considering the restriction $\mu_{K}^{R}>0$, $\forall K$ in combination with the three other identification restrictions.

(a) Mean probability of regions assigned to a group according to the highest probability.

(b) Mean probability of regions assigned to a group according to a probability above than 0.5 .

(b) Mean probability of regions non-assigned to a group with probability lower than 0.5.

(d) Percentage of regions that are not unambiguously assigned, because their maximum probability is below than 0.5 . 


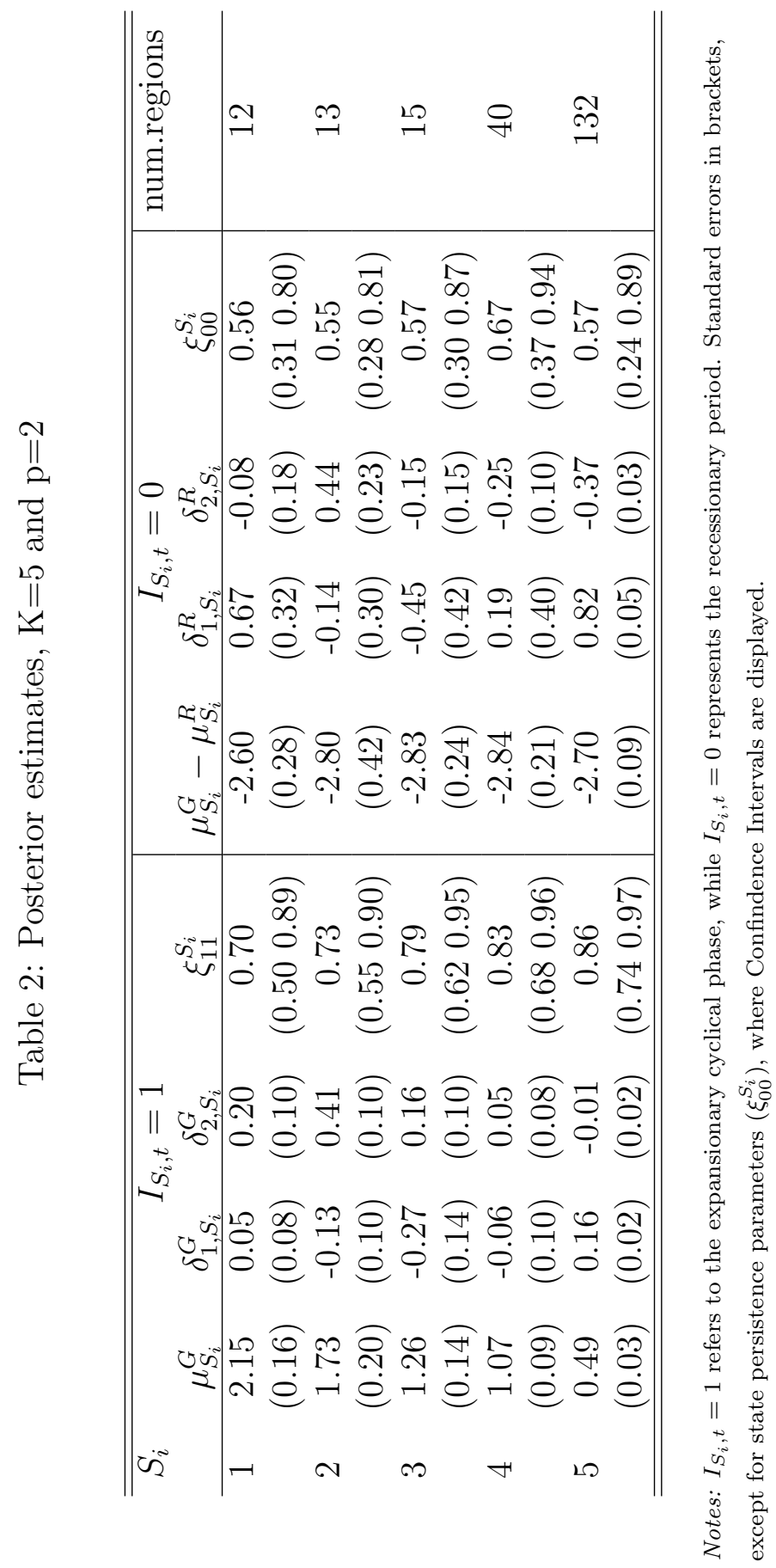




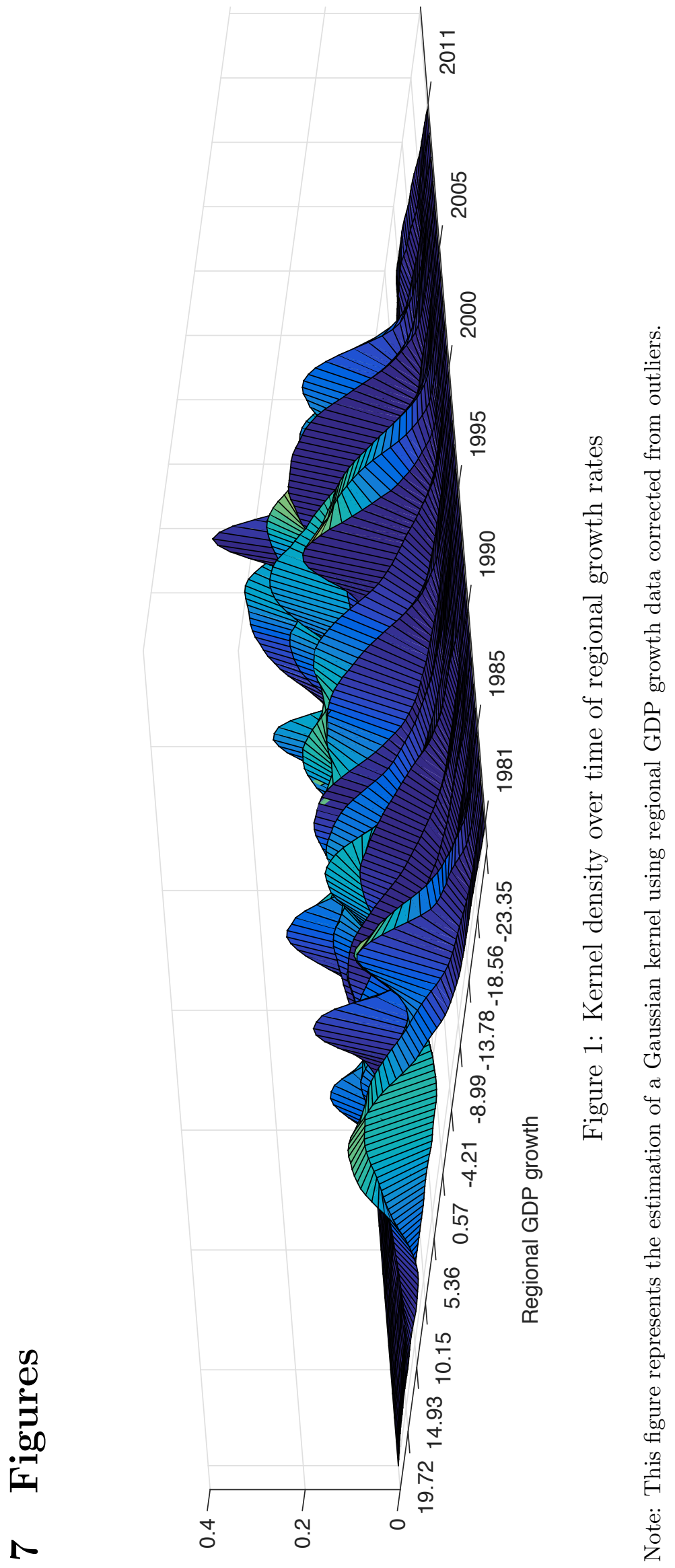



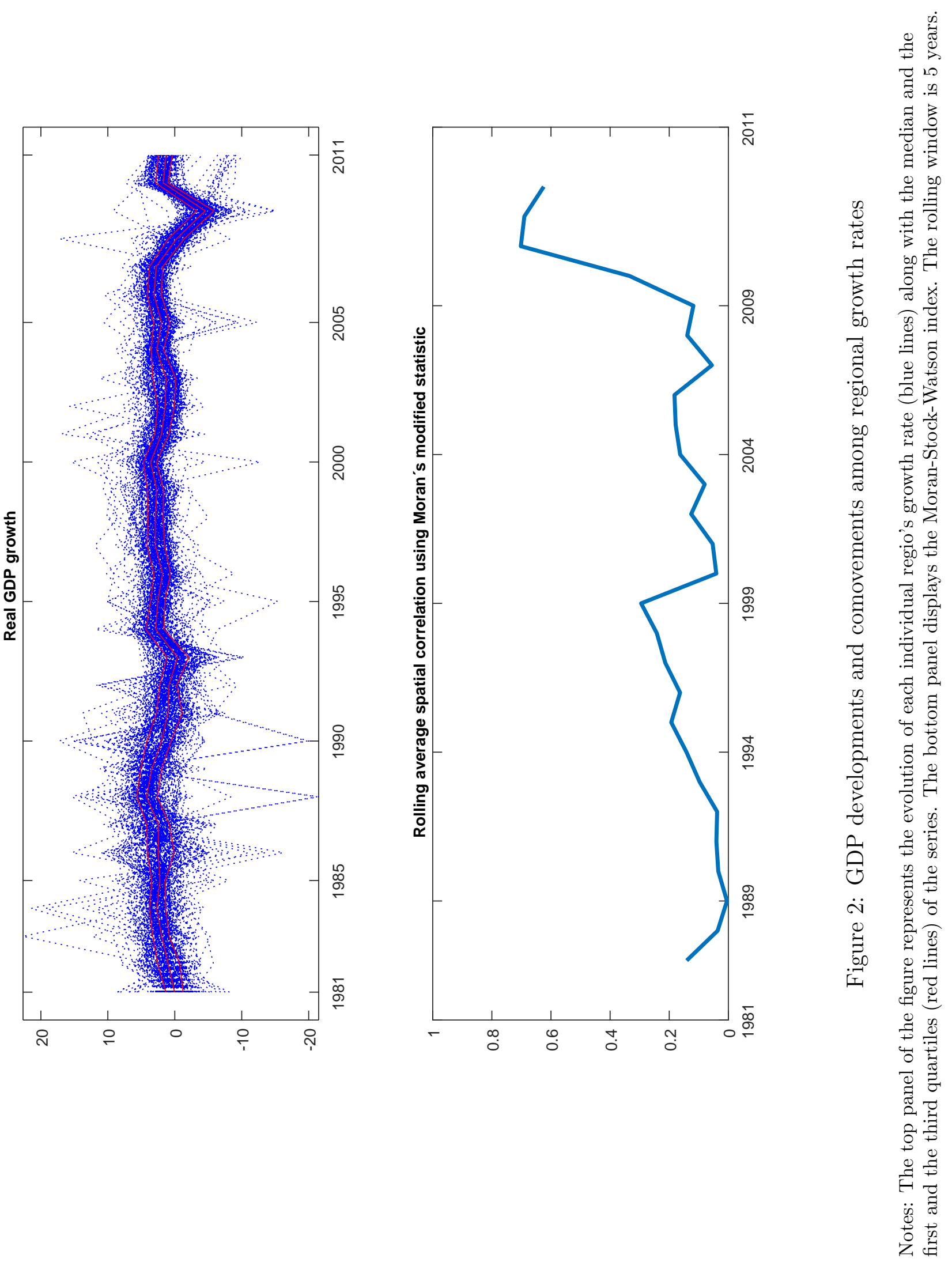


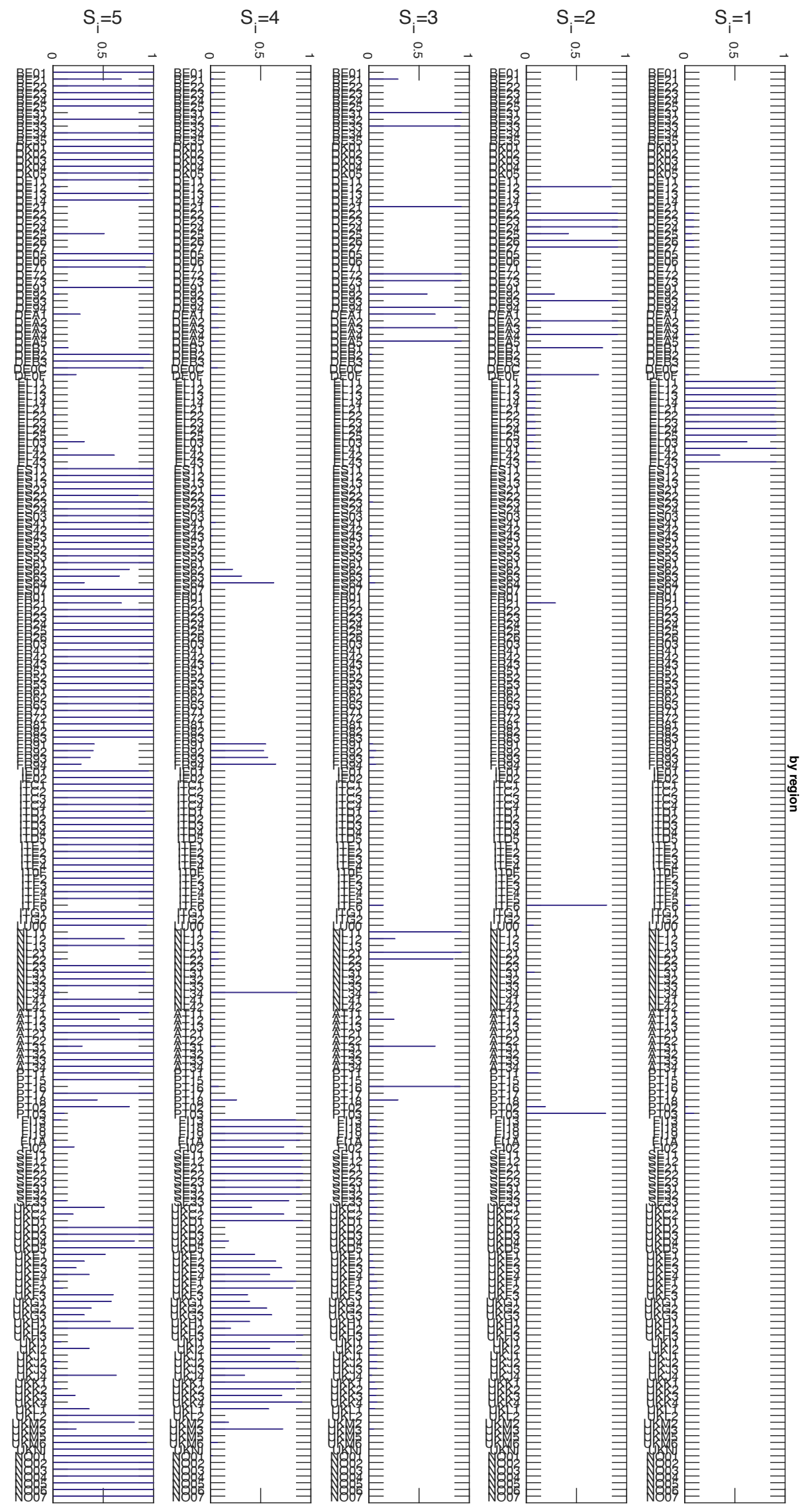

Figure 3: Probability by region of belonging to each group

Note: This figure displays the probability of each region of belonging to each group. 


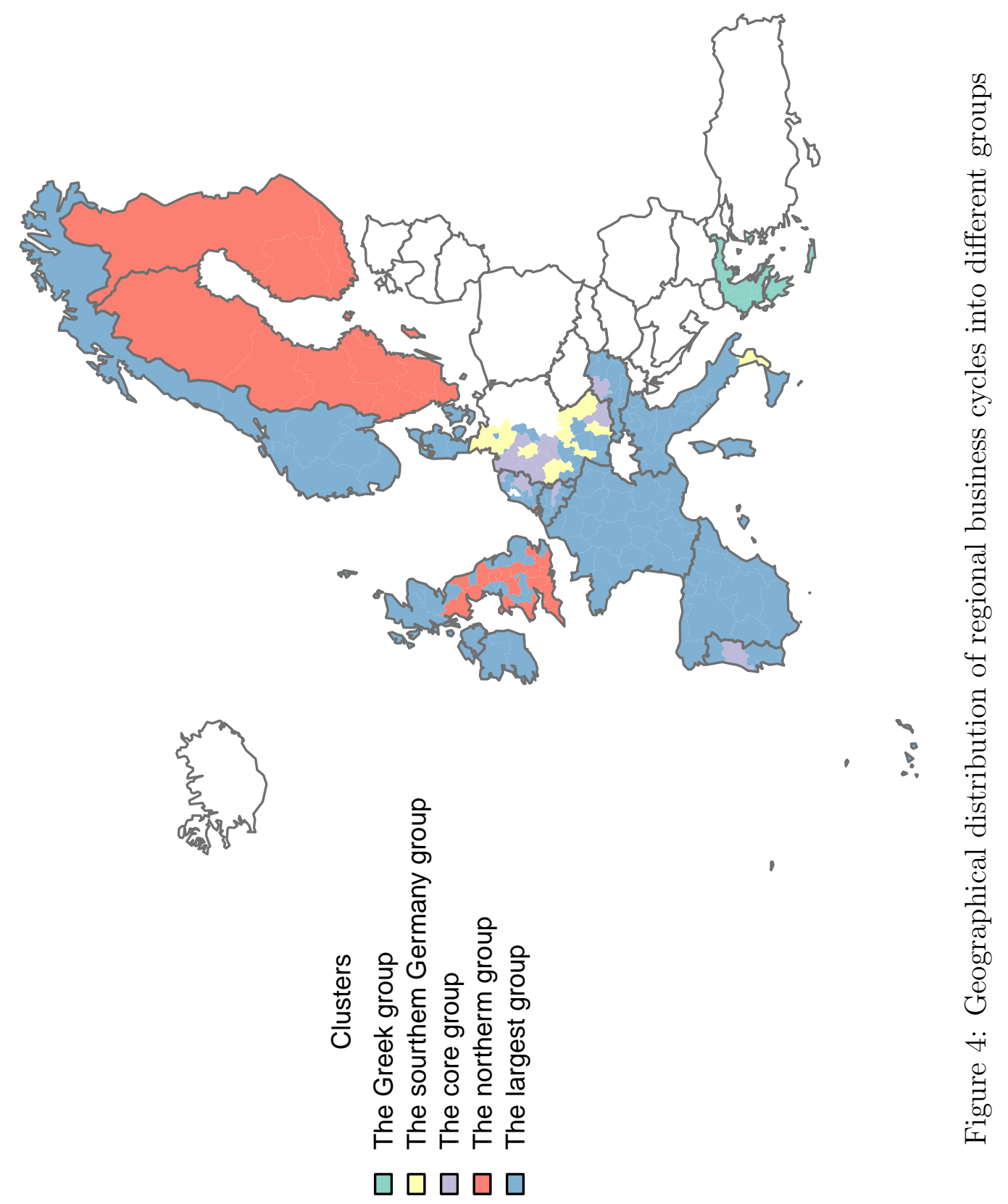




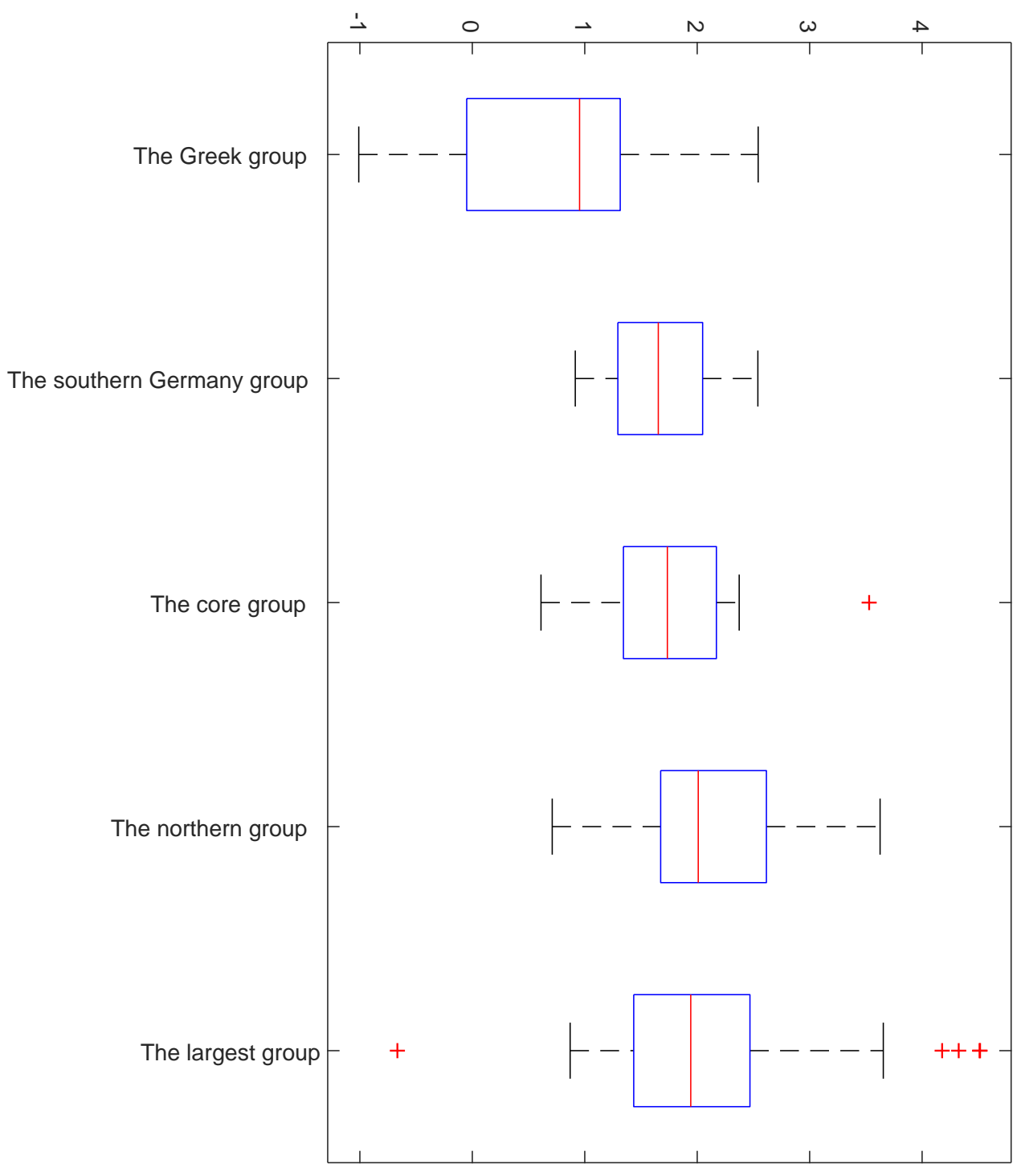

Figure 5: Average real GDP growth by group

Notes: The body of the boxplot is represented by a blue box, which goes from the first quartile (25\% of the data below this value) to the third quartile ( $25 \%$ of the data above this value) and the red line inside the box represents the median ( $50 \%$ of the data is greater than that value, that is, it is the middle of the dataset). Two horizontal lines, in dotted lines, ending in whiskers, extend from the upper side and the lower side of the box. The lower whisker goes from the first quartile to the smallest non-outlier in the dataset (the minimum value excluding outliers) and the upper whisker goes from the third quartile to the largest non-outlier of the sample (the maximum value excluding outliers). Outliers are plotted separately as red crosses on the chart. 

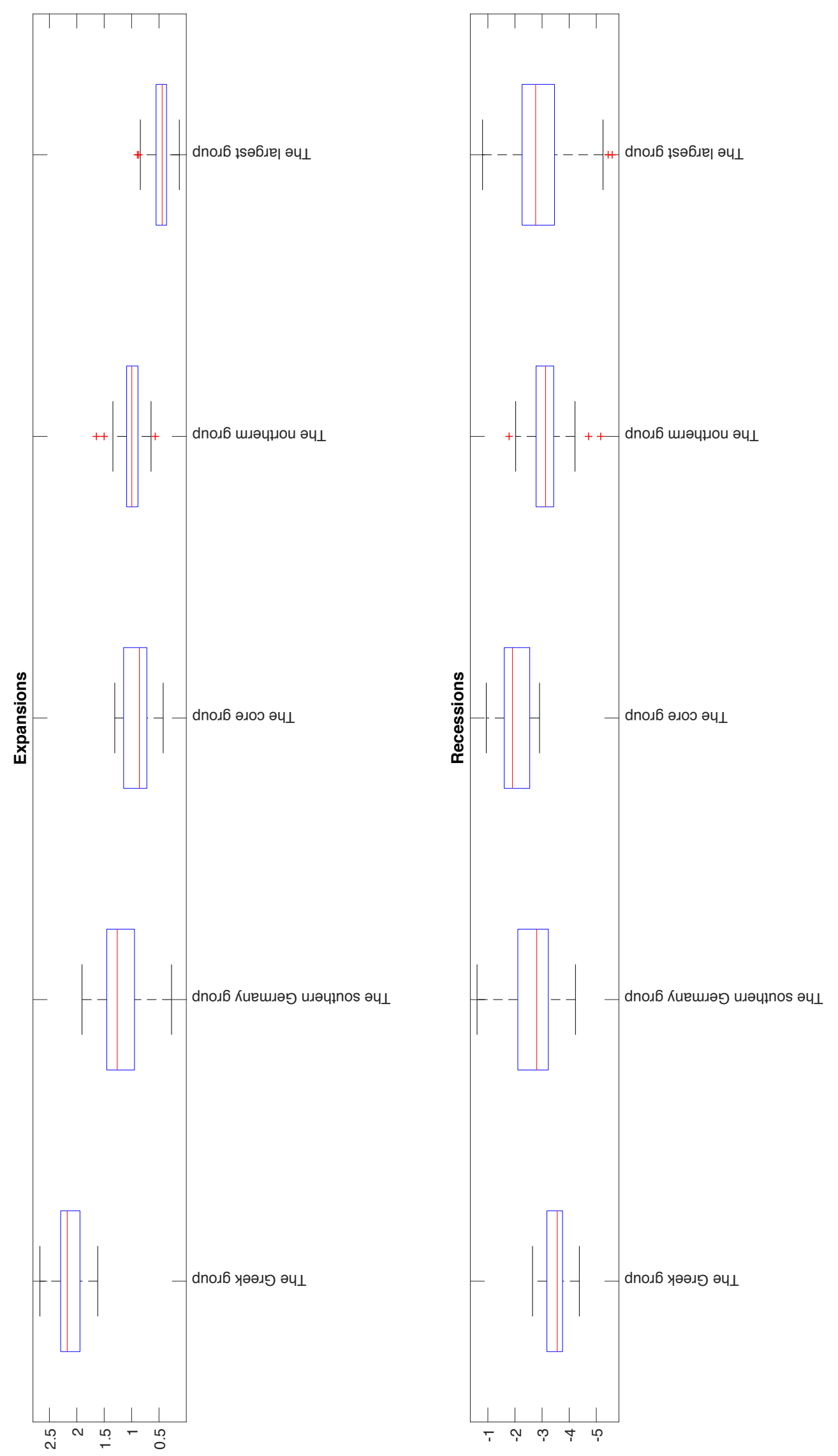

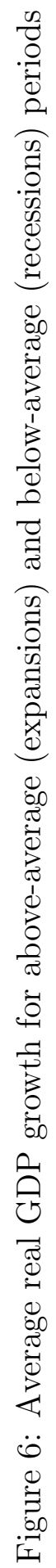




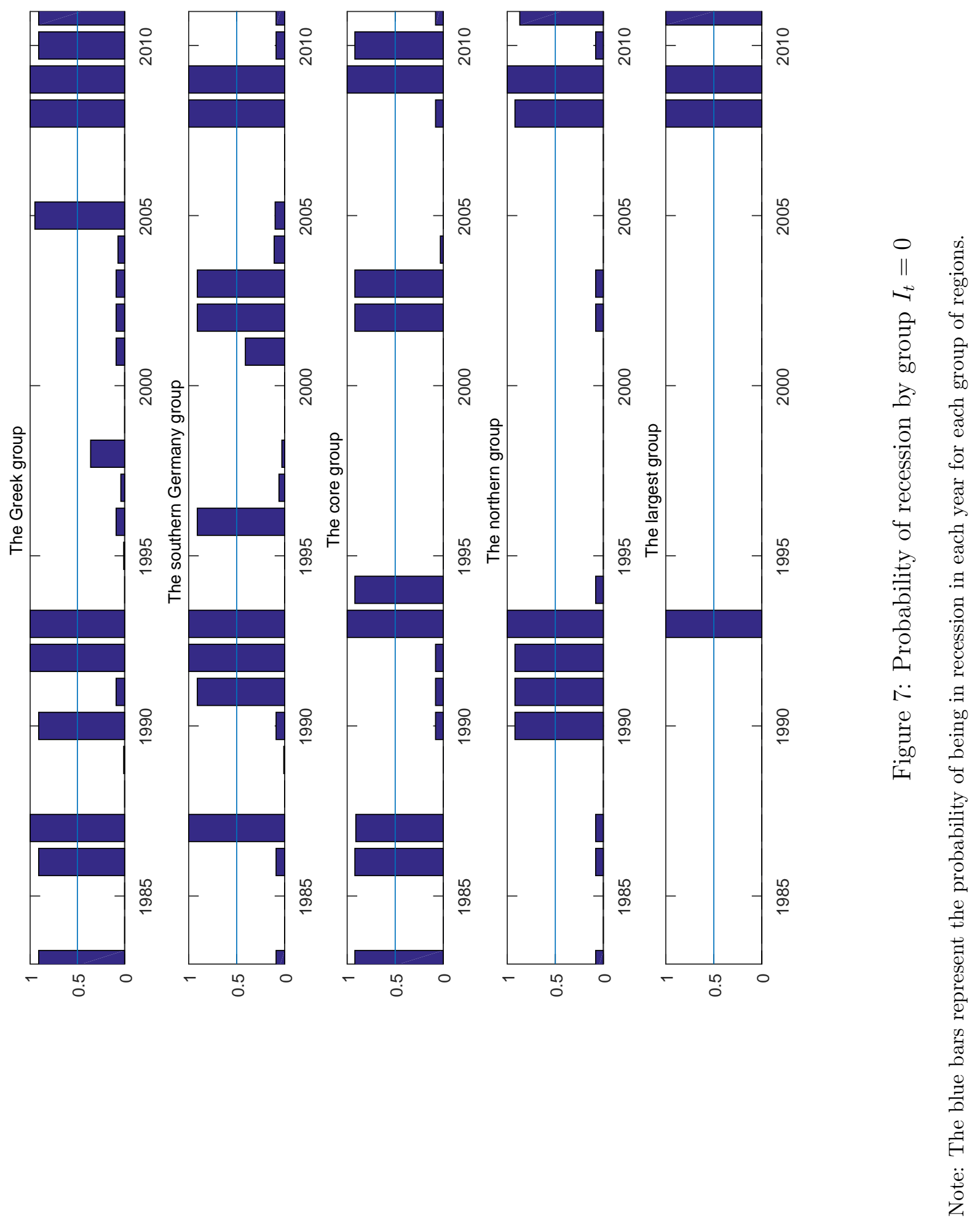




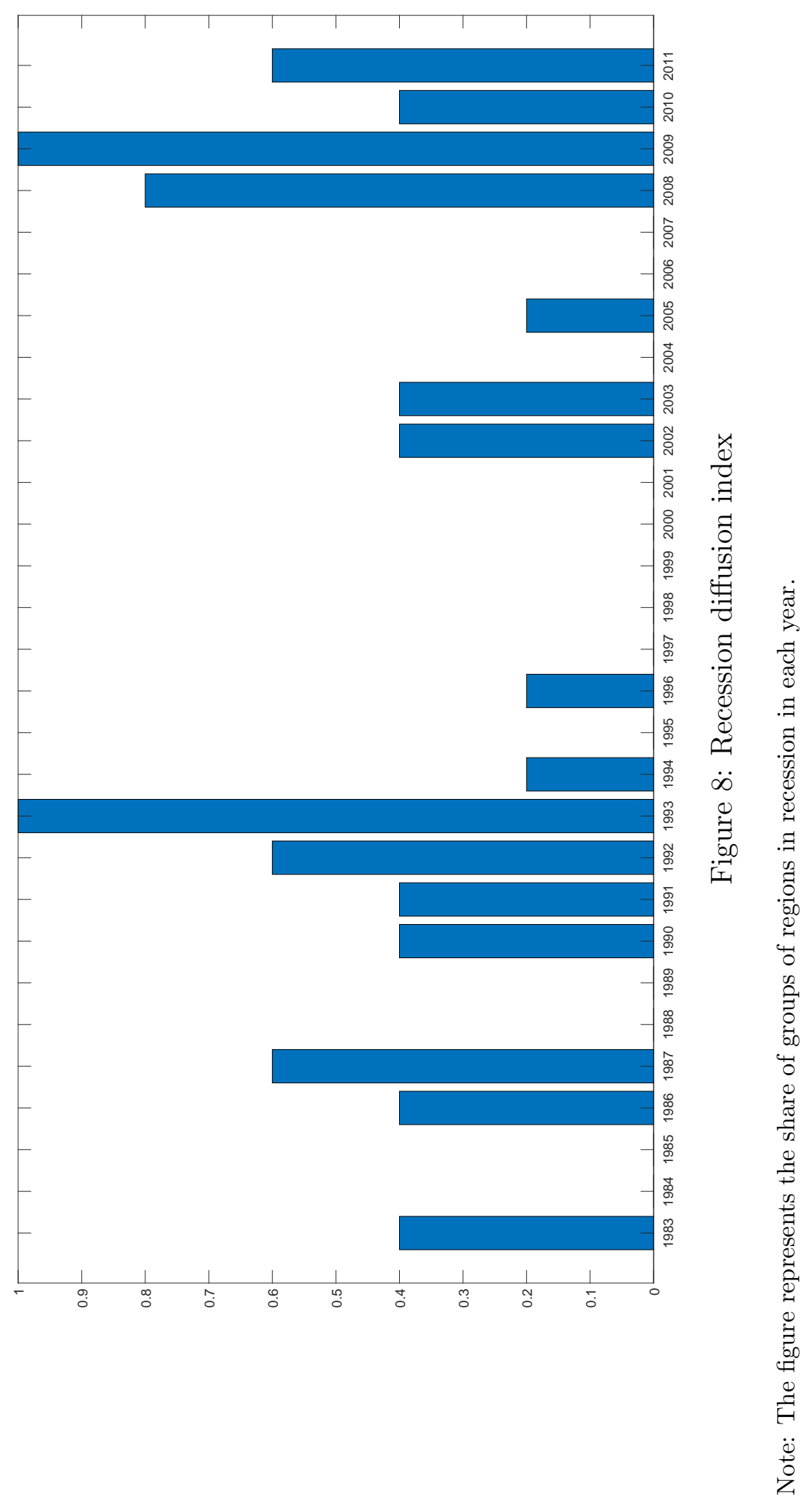




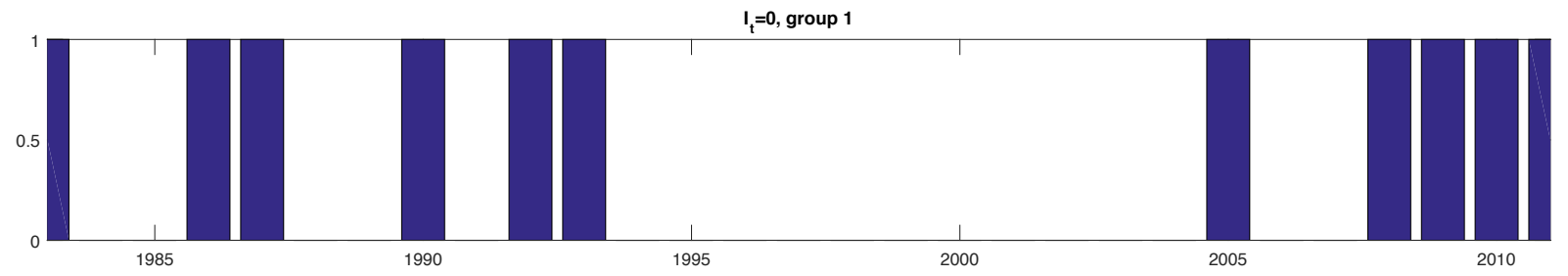

(a) The Greek group

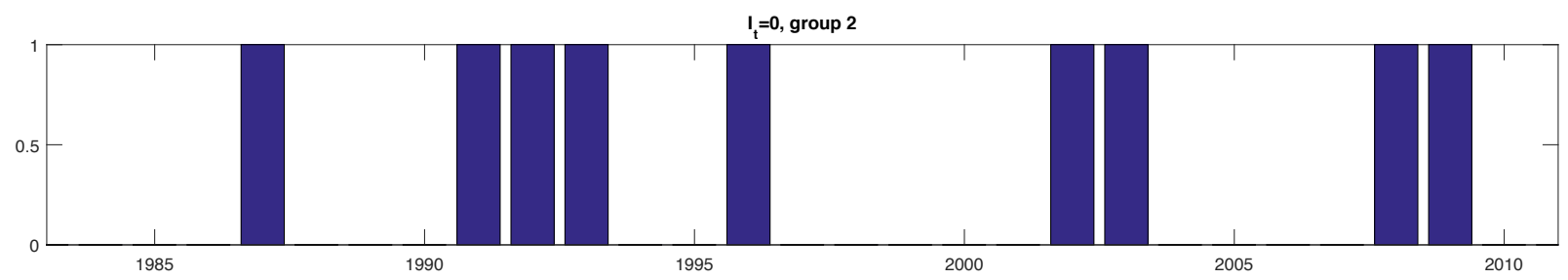

(b) The southern Germany group

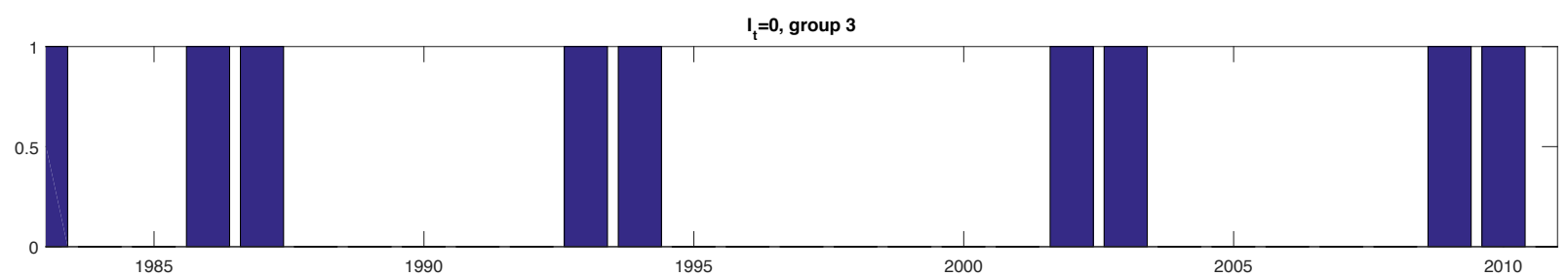

(c) The core group

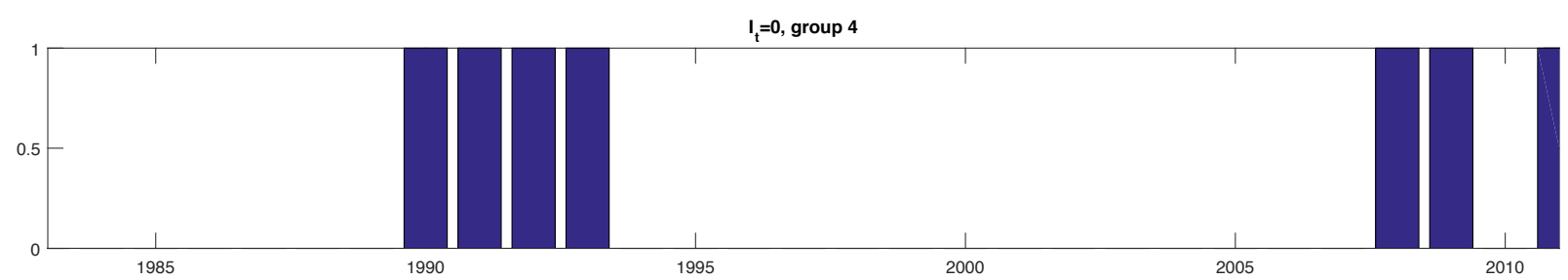

(d) The northern group

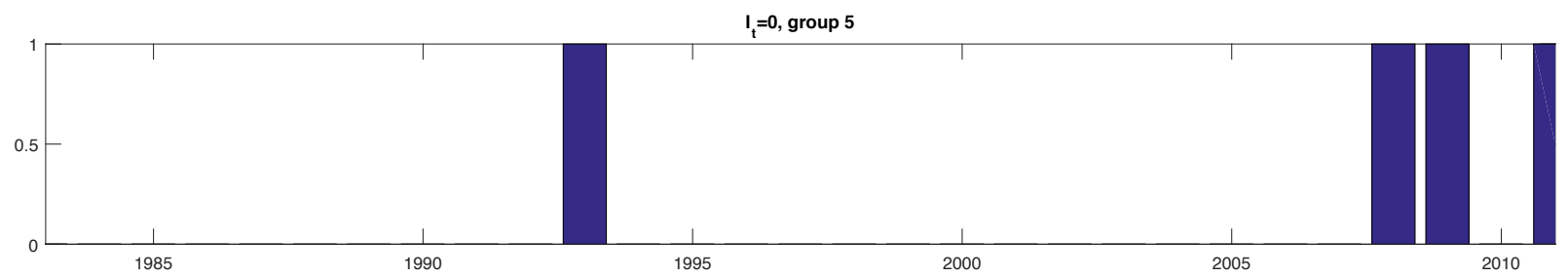

(e) The largest group

Figure 9: Business cycles of the different groups

Note: The blue bars represent years of recession for each group of regions. 


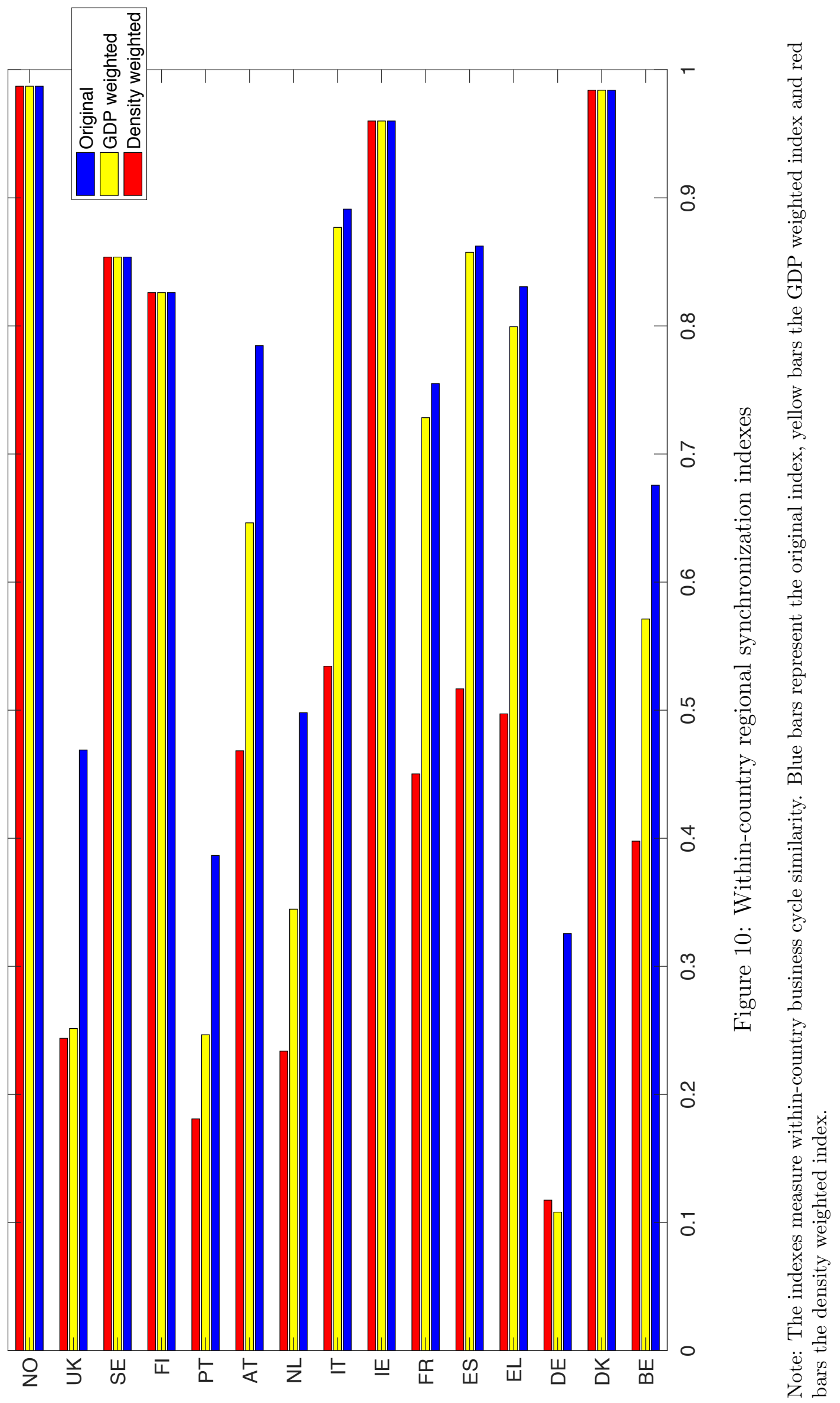




\section{Appendix: Probability by region of being in each group}

\begin{tabular}{|c|c|c|c|c|c|c|}
\hline & & G1 & G2 & G3 & G4 & G5 \\
\hline$\overline{\mathrm{BE} 01}$ & RÉGION DE BRUXELLES-CAPITALE / BRUSSELS HOOFDSTEDELIJK GEWEST & 0 & 0 & 0 & 0 & 1 \\
\hline BE21 & Prov. Antwerpen & 0 & 0 & 0.29 & 0.03 & 0.68 \\
\hline BE22 & Prov. Limburg (B) & 0 & 0 & 0 & 0 & 1 \\
\hline $\mathrm{BE} 23$ & Prov. Oost-Vlaanderen & 0 & 0 & 0 & 0.03 & 0.97 \\
\hline BE24 & Prov. Vlaams-Brabant & 0 & 0 & 0 & 0 & 1 \\
\hline BE25 & Prov. West-Vlaanderen & 0 & 0.01 & 0 & 0 & 0.99 \\
\hline BE31 & Prov. Brabant Wallon & 0 & 0 & 0.92 & 0.08 & 0 \\
\hline BE32 & Prov. Hainaut & 0 & 0 & 0 & 0 & 1 \\
\hline BE33 & Prov. Liège & 0 & 0 & 0.91 & 0.08 & 0.01 \\
\hline BE34 & Prov. Luxembourg (B) & 0 & 0 & 0 & 0 & 1 \\
\hline BE35 & Prov. Namur & 0 & 0 & 0 & 0 & 1 \\
\hline $\begin{array}{l}\text { DK01 } \\
\end{array}$ & Hovedstaden & $\overline{0}$ & 0.01 & 0 & $\overline{0}$ & 0.99 \\
\hline DK02 & Sjælland & 0 & 0 & 0 & 0.01 & 0.99 \\
\hline DK03 & Syddanmark & 0 & 0 & 0 & 0 & 1 \\
\hline DK04 & Midtjylland & 0 & 0 & 0 & 0 & 1 \\
\hline DK05 & Nordjylland & 0 & 0 & 0 & 0.01 & 0.99 \\
\hline DE11 & Stuttgart & 0 & 0 & 0 & 0.05 & 0.95 \\
\hline DE12 & Karlsruhe & 0.07 & 0.85 & 0.01 & 0 & 0.07 \\
\hline DE13 & Freiburg & 0 & 0.04 & 0 & 0.01 & 0.95 \\
\hline DE14 & Tübingen & 0 & 0.01 & 0 & 0 & 0.99 \\
\hline DE21 & Oberbayern & 0 & 0 & 0.92 & 0.08 & 0 \\
\hline DE22 & Niederbayern & 0.09 & 0.91 & 0 & 0 & 0 \\
\hline DE23 & Oberpfalz & 0.09 & 0.91 & 0 & 0 & 0 \\
\hline DE24 & Oberfranken & 0.09 & 0.91 & 0 & 0 & 0 \\
\hline DE25 & Mittelfranken & 0.07 & 0.42 & 0 & 0 & 0.51 \\
\hline DE26 & Unterfranken & 0.09 & 0.91 & 0 & 0 & 0 \\
\hline DE27 & Schwaben & 0.09 & 0.91 & 0 & 0 & 0 \\
\hline DE05 & BREMEN & 0 & 0 & 0 & 0 & 1 \\
\hline DE06 & HAMBURG & 0 & 0.01 & 0.01 & 0 & 0.98 \\
\hline DE71 & Darmstadt & 0.02 & 0.04 & 0.01 & 0.01 & 0.92 \\
\hline DE72 & Gießen & 0 & 0.02 & 0.92 & 0.06 & 0 \\
\hline DE73 & Kassel & 0 & 0 & 0.92 & 0.08 & 0 \\
\hline DE91 & Braunschweig & 0 & 0 & 0.01 & 0 & 0.99 \\
\hline DE92 & Hannover & 0.02 & 0.28 & 0.58 & 0.06 & 0.06 \\
\hline DE93 & Lüneburg & 0.09 & 0.91 & 0 & 0 & 0 \\
\hline DE94 & Weser-Ems & 0 & 0 & 0.92 & 0.08 & 0 \\
\hline DEA & Düsseldorf & 0 & 0 & 0.66 & 0.07 & 0.27 \\
\hline DEA: & Köln & 0.09 & 0.91 & 0 & 0 & 0 \\
\hline DEA: & Münster & 0 & 0.04 & 0.88 & 0.08 & 0 \\
\hline DEA & Detmold & 0.09 & 0.91 & 0 & 0 & 0 \\
\hline DEA: & Arnsberg & 0 & 0 & 0.92 & 0.08 & 0 \\
\hline DEB & Koblenz & 0.09 & 0.76 & 0 & 0 & 0.15 \\
\hline DEB: & Trier & 0 & 0 & 0.03 & 0.01 & 0.96 \\
\hline DEB: & Rheinhessen-Pfalz & 0 & 0 & 0.02 & 0.01 & 0.97 \\
\hline DE0C & SAARLAND & 0 & 0.02 & 0.01 & 0.07 & 0.9 \\
\hline DE0H & SCHLESWIG-HOLSTEIN & 0.04 & 0.72 & 0.01 & 0 & 0.23 \\
\hline$\overline{\text { EL11 }}$ & Anatoliki Makedonia, Thraki & 0.91 & 0.09 & 0 & $\overline{0}$ & 0 \\
\hline EL12 & Kentriki Makedonia & 0.9 & 0.09 & 0 & 0 & 0.01 \\
\hline EL13 & Dytiki Makedonia & 0.91 & 0.09 & 0 & 0 & 0 \\
\hline EL14 & Thessalia & 0.91 & 0.09 & 0 & 0 & 0 \\
\hline EL21 & Ipeiros & 0.91 & 0.09 & 0 & 0 & 0 \\
\hline EL22 & Ionia Nisia & 0.89 & 0.08 & 0 & 0 & 0.03 \\
\hline EL23 & Dytiki Ellada & 0.91 & 0.09 & 0 & 0 & 0 \\
\hline EL24 & Sterea Ellada & 0.91 & 0.09 & 0 & 0 & 0 \\
\hline EL25 & Peloponnisos & 0.91 & 0.09 & 0 & 0 & 0 \\
\hline EL03 & ATTIKI & 0.62 & 0.07 & 0 & 0 & 0.31 \\
\hline EL41 & Voreio Aigaio & 0.91 & 0.09 & 0 & 0 & 0 \\
\hline EL42 & Notio Aigaio & 0.35 & 0.03 & 0 & 0.01 & 0.61 \\
\hline EL43 & Kriti & 0.91 & 0.09 & 0 & 0 & 0 \\
\hline
\end{tabular}




\begin{tabular}{|c|c|c|c|c|c|c|}
\hline & & $\overline{\text { G1 }}$ & G2 & G3 & G4 & G5 \\
\hline ES11 & Galicia & 0 & 0 & 0 & 0 & 1 \\
\hline ES12 & Principado de Asturias & 0 & 0 & 0 & 0 & 1 \\
\hline ES13 & Cantabria & 0 & 0 & 0 & 0.01 & 0.99 \\
\hline ES21 & País Vasco & 0 & 0 & 0 & 0 & 1 \\
\hline $\mathrm{ES} 22$ & Comunidad Foral de Navarra & 0 & 0 & 0.01 & 0.14 & 0.85 \\
\hline ES23 & La Rioja & 0 & 0 & 0.04 & 0.02 & 0.94 \\
\hline ES24 & Aragón & 0 & 0 & 0 & 0 & 1 \\
\hline ES03 & COMUNIDAD DE MADRID & 0 & 0 & 0 & 0 & 1 \\
\hline ES41 & Castilla y León & 0 & 0 & 0 & 0.05 & 0.95 \\
\hline ES42 & Castilla-La Mancha & 0 & 0 & 0 & 0.01 & 0.99 \\
\hline ES43 & Extremadura & 0 & 0 & 0.03 & 0.02 & 0.95 \\
\hline ES51 & Cataluña & 0 & 0 & 0 & 0 & 1 \\
\hline ES52 & Comunidad Valenciana & 0 & 0 & 0 & 0 & 1 \\
\hline ES53 & Illes Balears & 0 & 0 & 0 & 0 & 1 \\
\hline ES61 & Andalucía & 0 & 0 & 0 & 0 & 1 \\
\hline ES62 & Región de Murcia & 0 & 0 & 0.02 & 0.22 & 0.76 \\
\hline ES63 & Ciudad Autónoma de Ceuta & 0 & 0.01 & 0.02 & 0.31 & 0.66 \\
\hline ES64 & Ciudad Autónoma de Melilla & 0 & 0 & 0.06 & 0.63 & 0.31 \\
\hline $\mathrm{ES} 07$ & CANARIAS & 0 & 0 & 0 & 0 & \\
\hline FR01 & ÎLE DE FRANCE & 0 & 0 & 0 & 0 & 1 \\
\hline FR21 & Champagne-Ardenne & 0.03 & 0.29 & 0 & 0 & 0.68 \\
\hline FR22 & Picardie & 0 & 0 & 0 & 0 & 1 \\
\hline FR23 & Haute-Normandie & 0 & 0 & 0 & 0 & ${ }^{1}$ \\
\hline FR24 & Centre & 0 & 0 & 0 & 0 & \\
\hline FR25 & Basse-Normandie & 0 & 0 & 0 & 0 & \\
\hline FR26 & Bourgogne & 0 & 0 & 0 & 0 & 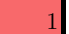 \\
\hline FR03 & NORD - PAS-DE-CALAIS & 0 & 0 & 0 & 0 & 1 \\
\hline FR41 & Lorraine & 0 & 0 & 0 & 0 & \\
\hline FR 42 & Alsace & 0 & 0 & 0 & 0 & 1 \\
\hline FR 43 & Franche-Comté & 0 & 0.01 & 0.01 & 0.03 & 0.95 \\
\hline FR51 & Pays de la Loire & 0 & 0 & 0 & 0 & 1 \\
\hline FR52 & Bretagne & 0 & 0 & 0 & 0 & \\
\hline FR53 & Poitou-Charentes & 0 & 0 & 0 & 0 & 1 \\
\hline FR61 & Aquitaine & 0 & 0 & 0 & 0 & 1 \\
\hline FR62 & Midi-Pyrénées & 0 & 0.01 & 0 & 0.03 & 0.96 \\
\hline FR63 & Limousin & 0 & 0 & 0 & 0 & 1 \\
\hline FR71 & Rhône-Alpes & 0 & 0 & 0 & 0 & 1 \\
\hline FR72 & Auvergne & 0 & 0 & 0 & 0 & 1 \\
\hline FR81 & Languedoc-Roussillon & 0 & 0.02 & 0 & 0 & 0.98 \\
\hline FR 82 & Provence-Alpes-Côte d'Azur & 0 & 0.01 & 0 & 0 & 0.99 \\
\hline FR83 & Corse & 0 & 0 & 0 & 0 & 1 \\
\hline FR91 & Guadeloupe & 0 & 0 & 0.04 & 0.55 & 0.41 \\
\hline FR92 & Martinique & 0 & 0 & 0.07 & 0.53 & 0.4 \\
\hline FR93 & Guyane & 0.01 & 0 & 0.05 & 0.57 & 0.37 \\
\hline FR94 & Réunion & 0 & 0 & 0.07 & 0.65 & 0.28 \\
\hline IE01 & Border, Midland and Western & 0.04 & 0.01 & 0 & 0 & 0.95 \\
\hline IE02 & Southern and Eastern & 0 & 0.01 & 0 & 0 & 0.99 \\
\hline
\end{tabular}




\begin{tabular}{|c|c|c|c|c|c|c|}
\hline & & G1 & G2 & G3 & G4 & G5 \\
\hline ITC1 & Piemonte & 0 & 0 & 0 & 0.01 & 0.99 \\
\hline ITC2 & Valle d'Aosta/Vallée d'Aoste & 0 & 0 & 0 & 0.01 & 0.99 \\
\hline ITC3 & Liguria & 0 & 0 & 0.02 & 0 & 0.98 \\
\hline ITC4 & Lombardia & 0 & 0 & 0 & 0.02 & 0.98 \\
\hline ITD1 & Provincia Autonoma Bolzano/Bozen & 0 & 0 & 0.08 & 0 & 0.92 \\
\hline ITD2 & Provincia Autonoma Trento & 0 & 0 & 0 & 0 & 1 \\
\hline ITD3 & Veneto & 0 & 0 & 0 & 0 & 1 \\
\hline ITD4 & Friuli-Venezia Giulia & 0 & 0 & 0 & 0.01 & 0.99 \\
\hline ITD5 & Emilia-Romagna & 0 & 0 & 0 & 0 & 1 \\
\hline ITE1 & Toscana & 0 & 0 & 0 & 0 & 1 \\
\hline ITE2 & Umbria & 0 & 0 & 0 & 0 & 1 \\
\hline ITE3 & Marche & 0 & 0 & 0 & 0.01 & 0.99 \\
\hline ITE4 & Lazio & 0 & 0 & 0 & 0 & 1 \\
\hline ITOF & SUD & 0 & 0 & 0 & 0 & 1 \\
\hline ITF2 & Molise & 0 & 0 & 0 & 0.01 & 0.99 \\
\hline ITF3 & Campania & 0 & 0 & 0 & 0 & 1 \\
\hline ITF4 & Puglia & 0 & 0 & 0 & 0.01 & 0.99 \\
\hline ITF5 & Basilicata & 0 & 0 & 0 & 0.01 & 0.99 \\
\hline ITF6 & Calabria & 0.06 & 0.8 & 0.14 & 0 & 0 \\
\hline ITG1 & Sicilia & 0 & 0 & 0 & 0 & 1 \\
\hline ITG2 & Sardegna & 0 & 0 & 0 & 0 & 1 \\
\hline LU00 & LUXEMBOURG (GRAND-DUCHÉ) & 0 & 0.07 & 0 & 0 & 0.93 \\
\hline NL11 & Groningen & $\overline{0}$ & $\overline{0}$ & 0.92 & 0.08 & 0 \\
\hline NL12 & Friesland (NL) & 0 & 0 & 0.26 & 0.03 & 0.71 \\
\hline NL13 & Drenthe & 0 & 0 & 0 & 0 & 1 \\
\hline NL21 & Overijssel & 0 & 0 & 0.92 & 0.08 & 0 \\
\hline NL22 & Gelderland & 0 & 0 & 0.84 & 0.08 & 0.08 \\
\hline NL23 & Flevoland & 0.01 & 0 & 0 & 0.03 & 0.96 \\
\hline NL31 & Utrecht & 0 & 0.08 & 0 & 0 & 0.92 \\
\hline NL32 & Noord-Holland & 0 & 0 & 0 & 0 & 1 \\
\hline NL33 & Zuid-Holland & 0 & 0 & 0 & 0 & 1 \\
\hline NL34 & Zeeland & 0 & 0 & 0.08 & 0.86 & 0.06 \\
\hline NL41 & Noord-Brabant & 0 & 0 & 0 & 0 & 1 \\
\hline NL42 & Limburg (NL) & 0 & 0 & 0 & 0.01 & 0.99 \\
\hline AT11 & Burgenland (A) & 0.04 & 0.01 & 0 & $\overline{0}$ & $\overline{0.95}$ \\
\hline AT12 & Niederösterreich & 0 & 0.05 & 0.25 & 0.04 & 0.66 \\
\hline AT13 & Wien & 0 & 0 & 0 & 0 & 1 \\
\hline AT21 & Kärnten & 0 & 0 & 0 & 0 & 1 \\
\hline AT22 & Steiermark & 0 & 0 & 0 & 0 & 1 \\
\hline AT31 & Oberösterreich & 0 & 0 & 0.66 & 0.05 & 0.29 \\
\hline AT32 & Salzburg & 0 & 0 & 0 & 0 & 1 \\
\hline AT33 & Tirol & 0 & 0 & 0 & 0 & 1 \\
\hline AT34 & Vorarlberg & 0 & 0 & 0 & 0 & 1 \\
\hline$\overline{P T 11}$ & Norte & 0.02 & 0.12 & $\overline{0}$ & $\overline{0}$ & $\overline{0.86}$ \\
\hline PT15 & Algarve & 0 & 0 & 0 & 0.01 & 0.99 \\
\hline PT16 & Centro $(\mathrm{P})$ & 0 & 0 & 0.91 & 0.08 & 0.01 \\
\hline PT17 & Lisboa & 0 & 0 & 0 & 0.01 & 0.99 \\
\hline PT18 & Alentejo & 0 & 0.01 & 0.29 & 0.26 & 0.44 \\
\hline $\mathrm{PT} 02$ & Região Autónoma dos AÇORES & 0.03 & 0.19 & 0 & 0.02 & 0.76 \\
\hline PT03 & Região Autónoma da MADEIRA & 0.09 & 0.79 & 0 & 0.01 & 0.11 \\
\hline$\overline{F I 13}$ & Itä-Suomi & $\overline{0}$ & $\overline{0}$ & 0.07 & 0.85 & $\overline{0.08}$ \\
\hline FI18 & Etelä-Suomi & 0 & 0 & 0.08 & 0.92 & 0 \\
\hline FI19 & Länsi-Suomi & 0 & 0 & 0.08 & 0.92 & 0 \\
\hline FI1A & Pohjois-Suomi & 0 & 0 & 0.08 & 0.89 & 0.03 \\
\hline $\mathrm{FI} 02$ & ÅLAND & 0.01 & 0 & 0.05 & 0.73 & 0.21 \\
\hline
\end{tabular}




\begin{tabular}{|c|c|c|c|c|c|c|}
\hline & & G1 & G2 & G3 & G4 & G5 \\
\hline SE11 & Stockholm & 0 & 0 & 0.08 & 0.91 & 0.01 \\
\hline SE12 & Östra Mellansverige & 0 & 0 & 0.07 & 0.92 & 0.01 \\
\hline SE21 & Småland med öarna & 0 & 0 & 0.08 & 0.9 & 0.02 \\
\hline SE22 & Sydsverige & 0 & 0 & 0.08 & 0.92 & 0 \\
\hline SE23 & Västsverige & 0 & 0 & 0.08 & 0.92 & 0 \\
\hline SE31 & Norra Mellansverige & 0 & 0 & 0.08 & 0.89 & 0.03 \\
\hline SE32 & Mellersta Norrland & 0 & 0.01 & 0.08 & 0.91 & 0 \\
\hline SE33 & Övre Norrland & 0 & 0.04 & 0.05 & 0.78 & 0.13 \\
\hline UKC1 & Tees Valley and Durham & 0 & 0 & 0.08 & 0.41 & 0.51 \\
\hline UKC2 & Northumberland and Tyne and Wear & 0 & 0 & 0.07 & 0.73 & 0.2 \\
\hline UKD1 & Cumbria & 0 & 0 & 0.08 & 0.92 & 0 \\
\hline UKD2 & Cheshire & 0 & 0 & 0 & 0 & 1 \\
\hline UKD3 & Greater Manchester & 0 & 0 & 0 & 0 & 1 \\
\hline UKD4 & Lancashire & 0 & 0 & 0.01 & 0.18 & 0.81 \\
\hline UKD5 & Merseyside & 0 & 0 & 0 & 0 & 1 \\
\hline UKE1 & East Yorkshire and Northern Lincolnshire & 0 & 0 & 0.04 & 0.44 & 0.52 \\
\hline UKE2 & North Yorkshire & 0 & 0 & 0.04 & 0.65 & 0.31 \\
\hline UKE3 & South Yorkshire & 0 & 0 & 0.06 & 0.71 & 0.23 \\
\hline UKE4 & West Yorkshire & 0 & 0 & 0.05 & 0.59 & 0.36 \\
\hline UKF1 & Derbyshire and Nottinghamshire & 0 & 0.01 & 0.08 & 0.85 & 0.06 \\
\hline UKF2 & Leicestershire, Rutland and Northamptonshire & 0 & 0 & 0.08 & 0.82 & 0.1 \\
\hline UKF3 & Lincolnshire & 0 & 0 & 0.03 & 0.37 & 0.6 \\
\hline UKG1 & Herefordshire, Worcestershire and Warwickshire & 0 & 0 & 0.03 & 0.39 & 0.58 \\
\hline UKG2 & Shropshire and Staffordshire & 0 & 0 & 0.06 & 0.56 & 0.38 \\
\hline UKG3 & West Midlands & 0 & 0 & 0.08 & 0.61 & 0.31 \\
\hline UKH1 & East Anglia & 0 & 0 & 0.04 & 0.39 & 0.57 \\
\hline UKH2 & Bedfordshire and Hertfordshire & 0 & 0 & 0 & 0.2 & 0.8 \\
\hline UKH3 & Essex & 0 & 0 & 0.08 & 0.92 & 0 \\
\hline UKI1 & Inner London & 0 & 0 & 0.08 & 0.84 & 0.08 \\
\hline UKI2 & Outer London & 0 & 0 & 0.05 & 0.59 & 0.36 \\
\hline UKJ1 & Berkshire, Buckinghamshire and Oxfordshire & 0 & 0 & 0.08 & 0.91 & 0.01 \\
\hline UKJ2 & Surrey, East and West Sussex & 0 & 0 & 0.08 & 0.85 & 0.07 \\
\hline UKJ3 & Hampshire and Isle of Wight & 0 & 0 & 0.08 & 0.88 & 0.04 \\
\hline UKJ4 & Kent & 0 & 0 & 0.03 & 0.34 & 0.63 \\
\hline UKK1 & Gloucestershire, Wiltshire and Bristol/Bath area & 0 & 0 & 0.06 & 0.9 & 0.04 \\
\hline UKK2 & Dorset and Somerset & 0 & 0 & 0.08 & 0.84 & 0.08 \\
\hline UKK3 & Cornwall and Isles of Scilly & 0 & 0 & 0.07 & 0.71 & 0.22 \\
\hline UKK4 & Devon & 0 & 0 & 0.08 & 0.91 & 0.01 \\
\hline UKL1 & West Wales and The Valleys & 0 & 0 & 0.06 & 0.58 & 0.36 \\
\hline UKL2 & East Wales & 0 & 0 & 0 & 0 & 1 \\
\hline UKM2 & Eastern Scotland & 0 & 0 & 0.01 & 0.18 & 0.81 \\
\hline UKM3 & South Western Scotland & 0 & 0 & 0.05 & 0.72 & 0.23 \\
\hline UKM5 & North Eastern Scotland & 0 & 0 & 0.01 & 0 & 0.99 \\
\hline UKM6 & Highlands and Islands & 0 & 0 & 0 & 0.07 & 0.93 \\
\hline UKN & Northern Ireland & 0 & 0 & 0 & 0 & 1 \\
\hline NO01 & Oslo og Akershus & 0 & 0 & 0 & 0.02 & 0.98 \\
\hline $\mathrm{NO} 02$ & Hedmark og Oppland & 0 & 0 & 0 & 0 & 1 \\
\hline NO03 & Sør-Østlandet & 0 & 0 & 0 & 0 & 1 \\
\hline NO04 & Agder og Rogaland & 0 & 0 & 0 & 0 & 1 \\
\hline NO05 & Vestlandet & 0 & 0 & 0 & 0 & 1 \\
\hline NO06 & Trøndelag & 0 & 0 & 0 & 0 & 1 \\
\hline $\mathrm{NO} 07$ & Nord-Norge & 0 & 0 & 0 & 0 & 1 \\
\hline
\end{tabular}

